SAND93-1044

Distribution

Unlimited Release

Printed July 1993

Category UC 702

\title{
Volatile Organic Monitor For Industrial Effluents
}

\author{
G. R. Laguna and F. J. Peter \\ Real-Time Monitors \& Controllers Department \\ A. D. Stuart \\ Programmers Department \\ V. M. Loyola \\ Environmental Monitoring Systems Department \\ Sandia National Laboratories \\ Albuquerque, NM 87185
}

\begin{abstract}
1990 amendments to the Clean Air Act have created the need for instruments capable of monitoring volatile organic compounds (VOCs) in public air space in an unattended and low cost manner. The purpose of the study was to develop and demonstrate the capability to do long term automatic and unattended ambient air monitoring using an inexpensive portable analytic system at a commercial manufacturing plant site. A gas chromatograph system, personal computer hardware, meteorology tower $\&$ instruments, and custom designed hardware and software were developed. Comparison with an EPA approved method was performed. The system was sited at an aircraft engines manufacturering site and operated in a completely unattended mode for 60 days. Two VOCs were monitored every 30 minutes during the $24 \mathrm{hr}$ day. Large variation in the concentration from $800 \mathrm{ppb}$ to the limits of detection of about $10 \mathrm{ppb}$ were observed. Work to increase the capabilities of the system is ongoing.
\end{abstract}




\section{Acknowledgements}

We thank Kathy Alam for her efforts as original principal investigator and as the point of contact to the external participants. Help with the weather station selection and field setup by Monty Apple, Hugh Church, and Mark Ivey is gratefully acknowledged. Mike Moulton's help in starting the project planning is appreciated. We thank Steve Thornberg for his patience in teaching us some gas chromatography fundamentals. Finally, we thank Mike Wherle's always quick response to our requests, Steve Walker's reasonableness in setting the goals of the effort and Julie Einerson's help during the field tests. 


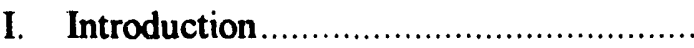

II. CRADA

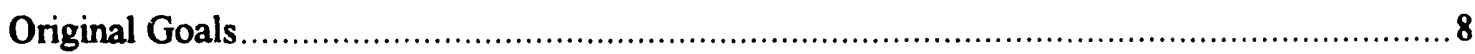

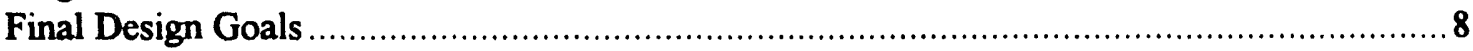

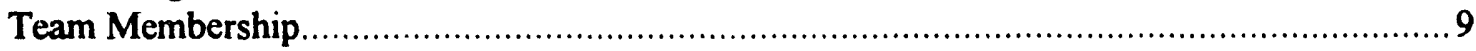

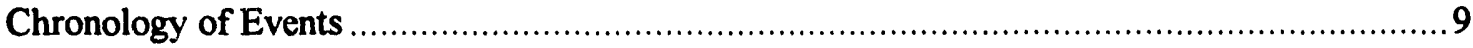

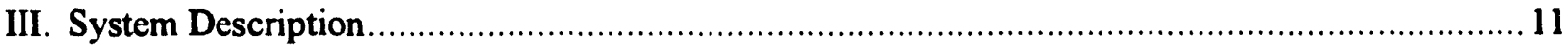

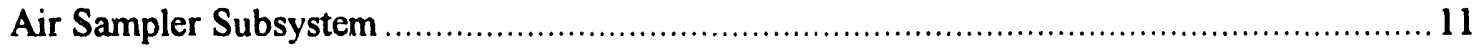

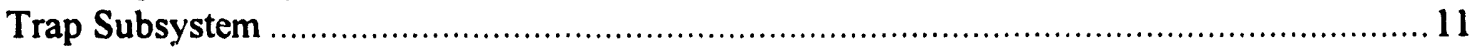

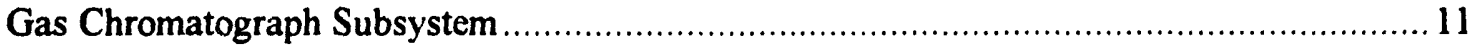

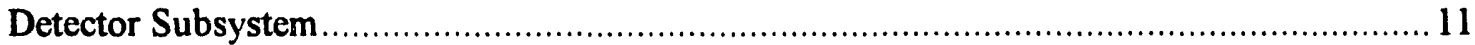

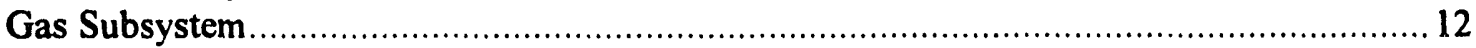

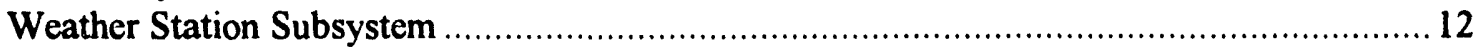

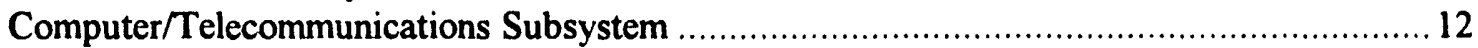

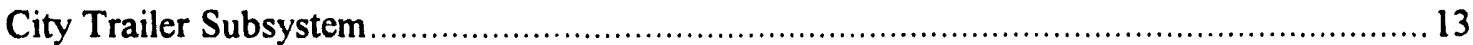

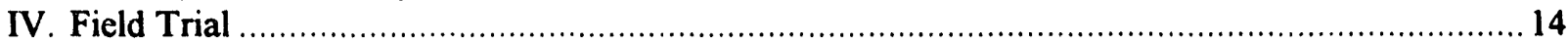

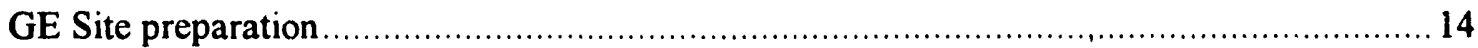

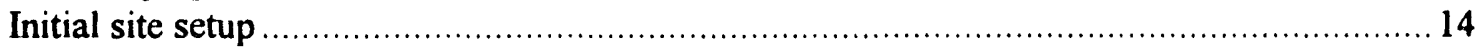

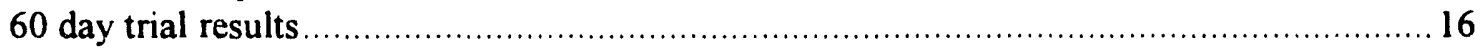

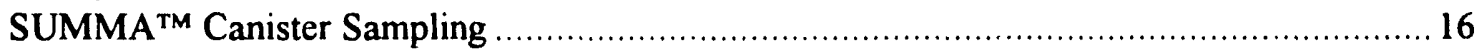

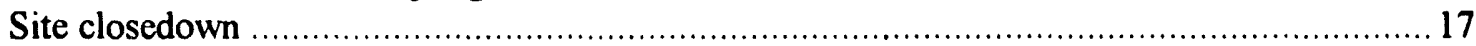

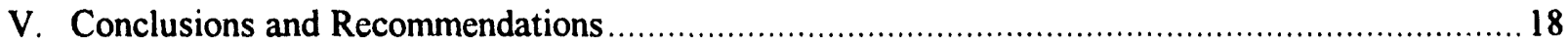

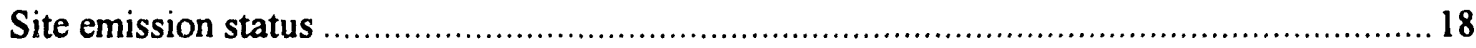

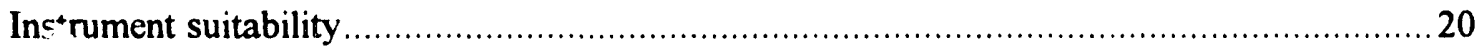

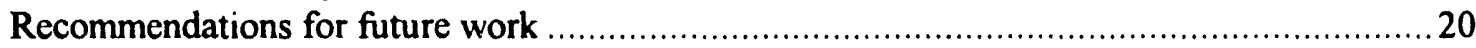

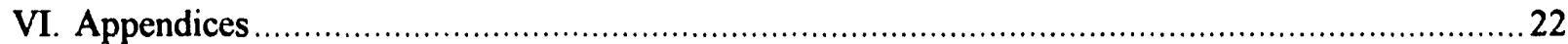

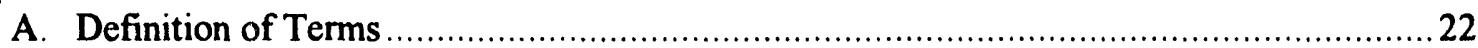

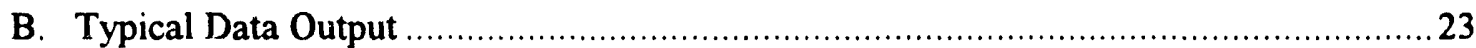

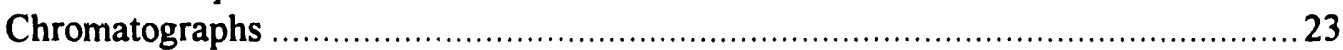

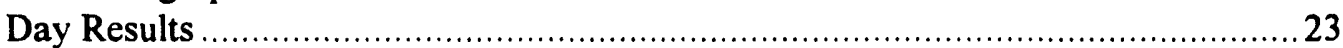

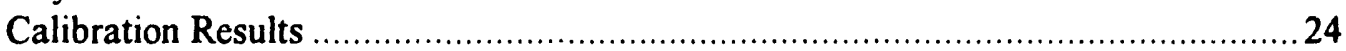

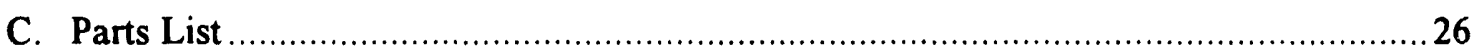

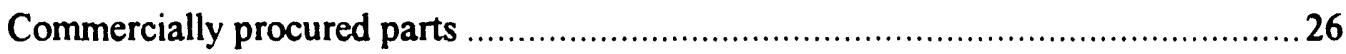

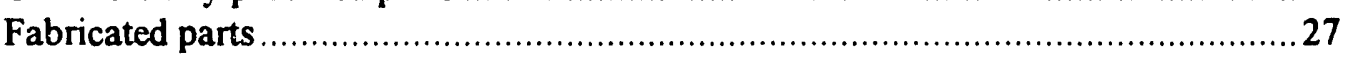

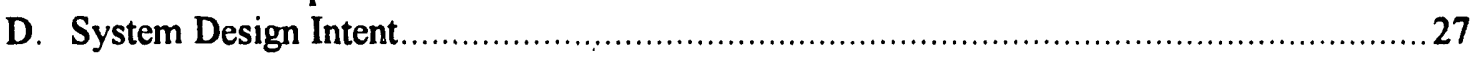

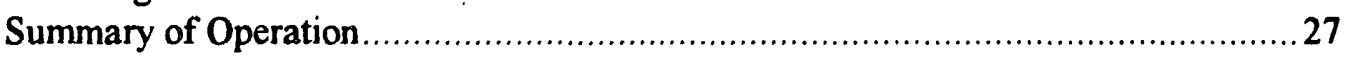

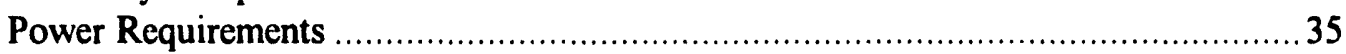

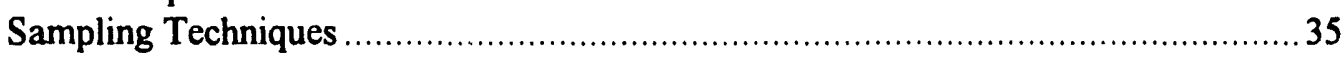

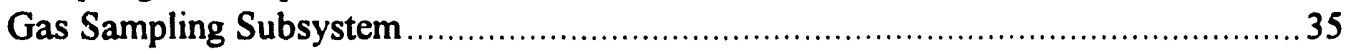

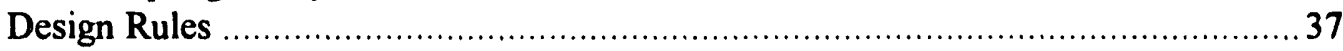

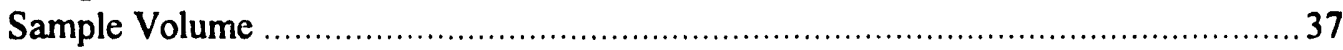

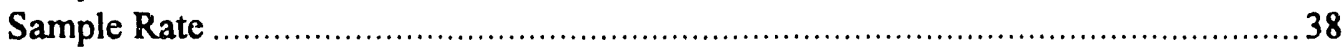

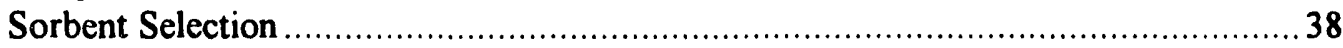

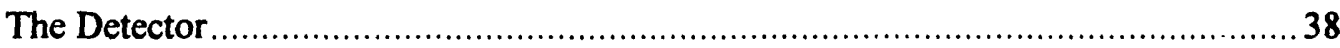

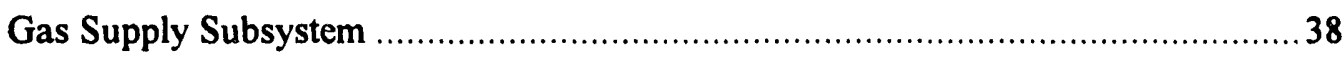

Tubing Cleaning and Checkout Procedure .......................................................40 40

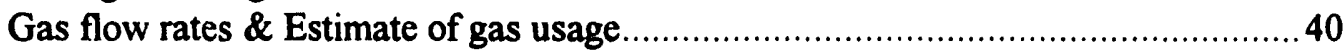

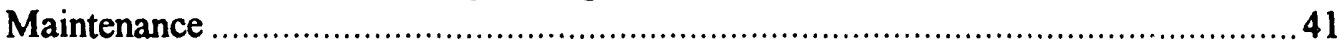




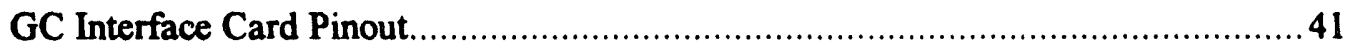

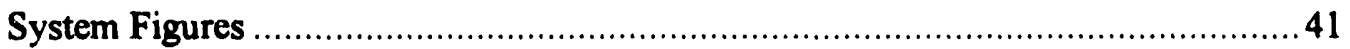

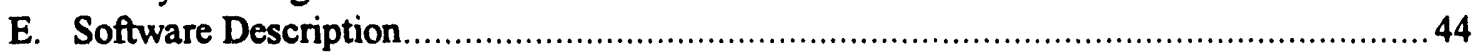

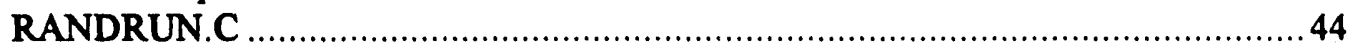

SuperKey Macros and Auto-Run Batch Files ............................................. 44

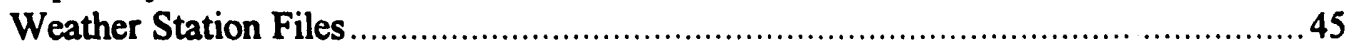

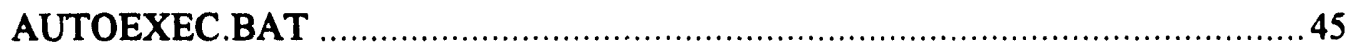

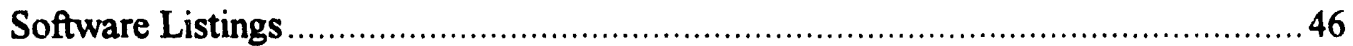

Figures

Figure 1. Schematic of GE site layout.

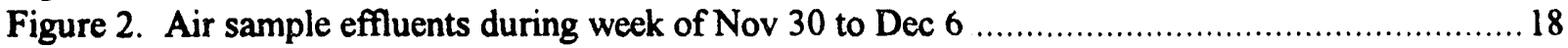

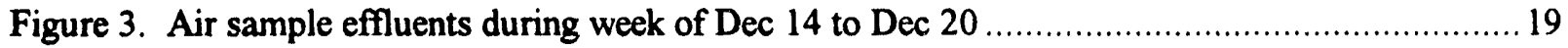

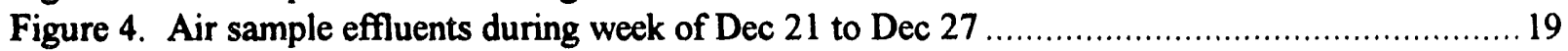

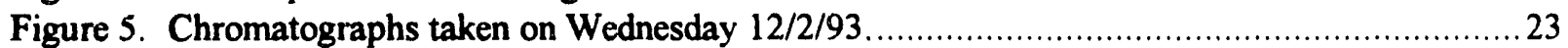

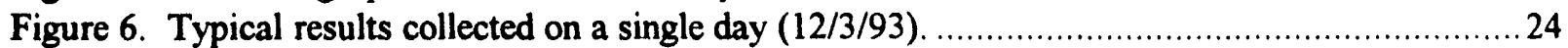

Figure 7. Calibration areas for MEK and 111-TCA for the 11/23 to 12/22 time period. .................25

Figure 8. Calibration peak times for MEK and 111-TCA for the 11/23 to 12/22 time period..........25

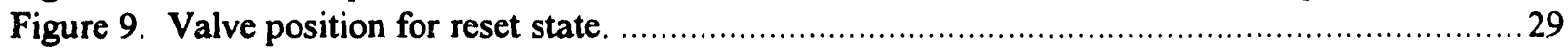

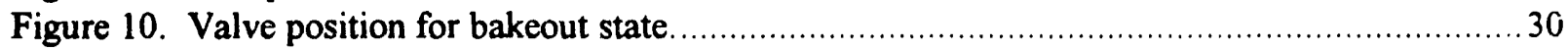

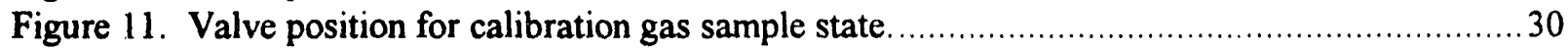

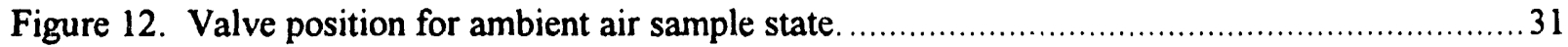

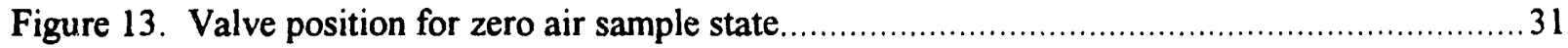

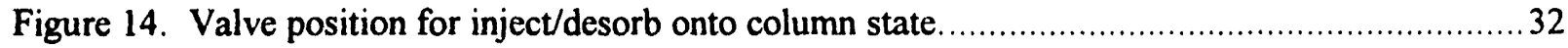

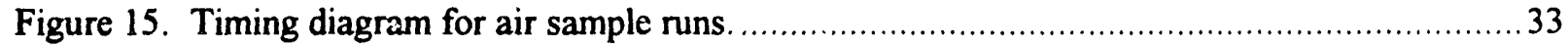

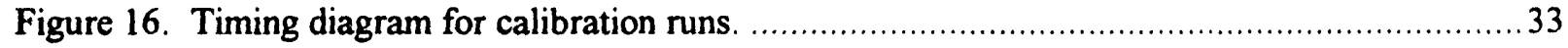

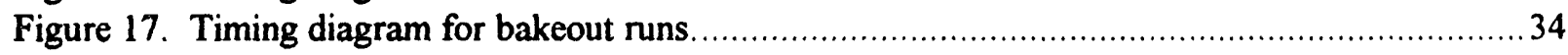

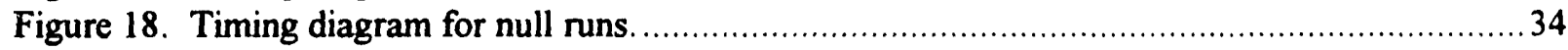

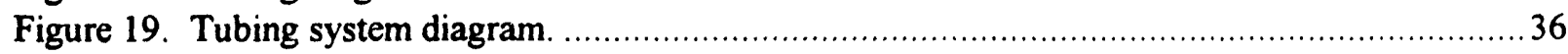

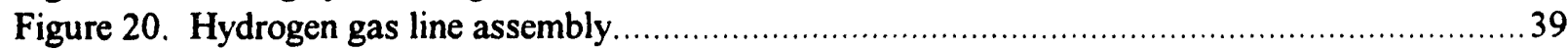

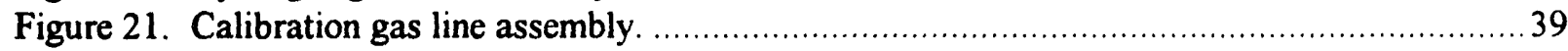

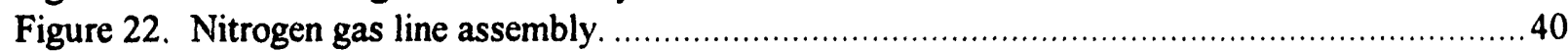

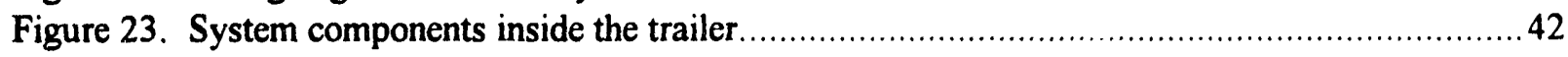

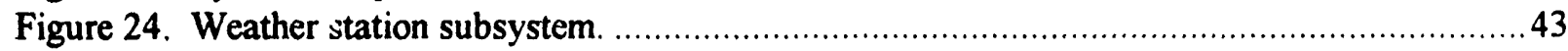




\section{Volatile Organic Monitor for Industrial Effluents}

\section{Introduction}

Congressional endorsement of the 1990 amendments to the Clean Air Act (CAA) will mean that state governments will be required to begin ambient air monitoring for the presence of the 189 new chemicals or type of chemicals which the CAA amendments will add to the list of hazardous pollutants. At the present time there are no criteria or National Ambient Air Quality Standards (NAAQS) established for most of these pollutants. It is anticipated, however, that if the amendments are passed each compound will be given a permissible level until scientifically determined criteria can be established. The most hazardous compounds, such as known carcinogens, will, of course, be given the lowest possible permissible levels.

At the present time most if not all EPA certified methods for monitoring ambient air are laboratory-based methods, i.e., they require separate and discontinuous sampling and analysis activities which are far from being real-time measurements. The ideal monitoring methodology for these compounds would be both EPA certified and as near real-time as possible.

This report documents the results of a Cooperative Research And Development Agreement (CRADA) which was undertaken by SNL and the City of Albuquerque (COA) to develop a system for monitoring ambient air for the presence of volatile organic compunds (VOCs). The intent was to develop and demonstrate the capability to do long-term $(\approx 30$ days), automatic and unattended ambient air monitoring using an inexpensive portable or transportable analytical system. 


\section{CRADA}

\section{Original Goals}

This work was a collaborative effort between the City of Albuquerque and SNL to build a system capable of measuring a large subset of airborne volatile organic compounds (VOCs) taken from a list of hazarilous airborne compounds. The large list of VOCs was taken from a proposed Urban Air Toxics Monitoring Program created by the Environmental Protection Agency (EPA) and is incorporated into the Clean Air Act Amendments of 1990. The chemical types (about 189 different chemicals of which about 100 are VOCs) and the required detection limits vary widely. Usage for the system was to be as an ambient air monitor. That is the system would be placed in public air space and monitor the air for the various VOCs of interest.

The initial proposal suggested using open-path Fourier Transform Infrared Spectrometry (FTIR) as the chemical sensing/measurement method and chemometric techniques as the analysis/data reduction method. Other techniques were to be investigated for suitability as well. It was also suggested that the system could be used at the DOE production agencies to monitor the public air space near the plants.

\section{Final Design Goals}

Due to various factors the final detection technique chosen was gas chromatography. Some of these factors were: open-path FTIR based monitoring is not an EPA approved method, high FTIR instrument cost, ppb chemical sensitivity, short time schedule considerations, but most especially the City's desire for unattended/automatic operation. The EPA does recognize a variety of gas chromatographic methods for ambient air monitoring. The chemical species measured was based upon the effluents emitted by the industrial site shosen by the City of Albuquerque. The GE Aerospace Division (336 Woodard Rd., SE, Albuquerque, NM) only emitted a limited number of effluents into the air in measurable quantities. We chose to measure: methyl ethyl ketone (MEK), and trichloroethane 1,1,1 (111-TCA). These two volatile organics can be well-separated by standard gas chromatograph columns. In addition, these chemicals are easily adsorbed (trapped) onto and desorbed from a carbon-based adsorbant. Adsorption can be achieved at room temperature and desorption can be accomplished at moderate temperatures. The method used in this study is a variation of accepted EPA methods.

Below is a listing of the technical goals.

- unattended/automatic operation (no operator intervention except for periodic maintenance and data interrogation)

- self-calibrating

- self-cleaning

- semi-portable (movable by single person, installation in temperature controlled trailer)

- real-time operation (all analysis performed on site)

- air sampling duty cycle as rapid as possible

- monitoring coordinated with meteorological data

- communicate remotely

- low maintenance (replaceable filters, replaceable gas cylinders, etc.) 
- low instrument cost

\section{Team Membership}

The design team consisted of personnel from three SNL centers: 1800,2300 , and 6600. 1800 personnel provided gas chromatography consulting, 2300 personnel provided the hardware design, system integration, and field testing work, and 6600 personnel provided external customer liaison, operations support, field siting guidance and weather station consulting and support. The personnel on the team were:

\begin{tabular}{|c|l|}
\hline Department & \multicolumn{1}{c|}{ Personnel } \\
\hline 1823 & $\begin{array}{l}\text { Kathy Alam } \\
\text { Susan Bender } \\
\text { Steve Thornberg }\end{array}$ \\
\hline 2314 & Angela Stuart \\
\hline 2337 & $\begin{array}{l}\text { George Laguna } \\
\text { Frank Peter }\end{array}$ \\
\hline 6612 & $\begin{array}{l}\text { Monty Apple } \\
\text { Hugh Church } \\
\text { Mark Ivey } \\
\text { Vincent Loyola }\end{array}$ \\
\hline
\end{tabular}

External participants were: Mike Wehrle-City of Albuquerque technical consultant, and Julie Einerson-GE point of contact and facilitator.

\section{Chronology of Events}

The table below shows a monthly summary of the major activities and events throughout the project. Two major issues during the project were a) abandonment of the FTIR method and b) miscommunication of the chemicals in use at GE. The decision to abandon the FTIR approach in favor of the gas chromatography approach was due to low detection sensitivity and lack of automation in the FTIR instruments available. The error in communication between SNL and GE on the chemicals in use at GE caused an identification glitch for the first 3 weeks of the GE field trial, however, it did not affect the result that the system successfully ran continuously for the major portion of the trial.

\begin{tabular}{|l|l|}
\hline Month & \multicolumn{1}{|c|}{ Major Activity/Event } \\
\hline February 92 & $\begin{array}{l}\text { News conference announcing CRADA signing } \\
\text { Perform instrument manufacturer literature search }\end{array}$ \\
\hline March & Visit instrument manufacturers \\
\hline April & Decide on final group of potential instruments \\
\hline May & $\begin{array}{l}\text { Decide on SRI Gas Chromatograph/Deselect FTIR } \\
\text { Discuss technology shift w/SNL TACT representative } \\
\text { Get w/City to settle on technical goals } \\
\text { Choose GE as field trial site }\end{array}$ \\
\hline June & $\begin{array}{l}\text { Obtain list of VOC's to measure } \\
\text { Receive City trailer }\end{array}$ \\
\hline July & $\begin{array}{l}\text { Receive SRI Gas Chromatograph } \\
\text { Begin instrument characterization }\end{array}$ \\
\hline August & City trailer modifications complete \\
\hline
\end{tabular}




\begin{tabular}{|l|l|}
\hline Month & \multicolumn{1}{|c|}{ Major Activity/Event } \\
\hline September & Laboratory characterization \\
\hline October & $\begin{array}{l}\text { SNL field trial } \\
\text { Brief City personnel }\end{array}$ \\
\hline November & $\begin{array}{l}\text { Begin GE field trial 11/9 } \\
\text { Learn of chemical species miscommunication }\end{array}$ \\
\hline December & $\begin{array}{l}\text { Field trial continues } \\
\text { End field trial 12/22 }\end{array}$ \\
\hline January 93 & $\begin{array}{l}\text { Obtain SUMMA } \\
\text { Final report }\end{array}$ \\
\hline
\end{tabular}




\section{System Description}

The system consists of a number of well-defined subsystems: air sampler, trap, gas chromatograph, detector, gases, metereological station, and computer. Most of the subsystems consisted of purchased piece parts or instruments. Value was added in the system integration of units which are not designed to be used in an unattended mode of operation. Below is a simplified functional description of these subsystems. Appendix $\mathrm{C}$ lists the individual part numbers for all the equipment used in the various subsystems. Appendix D discusses the design intent for these subsystems as well as more detailed technical information about the operations and parameters of the subsystems. System and subsystem drawings are also shown in Appendix D.

\section{Air Sampler Subsystem}

The air sampler collects ambient air from the close surroundings of the intake port about 15feet above ground level. It draws air into a 1 -inch diameter glass tube at about 15 -liters per minute by a mechanical pump. Most of the gas is exhausted back into the atmosphere, but a small sample of about 100-milliliters per minute is pulled through the trap by another mechanical pump. The air sampler consists of a glass tube, a Teflon tube, a particulate filter trap, an impeller-type fan, a diaphragm type mechanical pump, intake \& exhaust nozzles, stainless steel tubes, a mass flow controller, and a six position electrically controlled valve. Air is continuously flowing through the glass tube and the secondary sampling piping. The valve is electrically controlled by the computer system. The mass flow controller is manually preset by its own separate controller. SNL designed and built this subsystem from procured piece parts.

\section{Trap Subsystem}

The trap is used to concentrate the organic volatiles from the 10-minute (maximum) sampling period. It is an activated carbon filter used at ambient temperature. It is surrounded by heating elements which provide an impulse heat influx to liberate the trapped material in a very short time. The volatiles are then piped into the chromatographic column. The heating elements are electricall'; controlled by the computer system. This subsystem was purchased as a part of the gas chromatograph.

\section{Gas Chromatograph Subsystem}

The unit consists of a housing, valves, an oven, various readouts, etc. Its vital element is the oven containing a capillary column (per EPA method 624 using a DB5 column-30-meter long with a $0.53-\mathrm{mm}$ diameter). It provides a time separation of the chemical species according to a complex relation between vapor pressure, boiling points, and chemical reactivity of the chemical of interest to the column materials. The oven temperature is controlled by the computer system. We chose to run the oven at a constant temperature $\left(40^{\circ} \mathrm{C}\right)$ which was possible because we only had to measure two chemical compounds. This subsystem determined the sampling repetition time since it exhibited the longest time constant of the various operations. This subsystem was purchased.

\section{Detector Subsystem}

A large number of different deteciors can be used at the output end of the chromatographic column. We procured three detector types that could have been used on the gas chromatograph unit: a photoionization detector (PID), a electron capture detector (ECD), and 
a flame ionization detector (FID) can be used to detect carbon containing chemicals. A typical laboratory configuration is to place a non-destructive detector like the PID and the destructive FID in series and in this order at the end of the column. This configuration allows for increased number of chemical species that can be detected. The output signals are signal conditioned and then fed to $A / D$ converters into a memory board for final readout into the computer system. During data collection, measurements are taken every 1 -second. We chose to use only the FID detector based upon its excellent sensitivity to the two chemicals we were interested in and the fact that its maintenance requirements are very low. The PID for example, requires that the quartz window be cleaned daily. This subsystem was purchased as a part of the gas chromatograph subsystem.

\section{Gas Subsystem}

Three high purity gases were used: hydrogen, nitrogen, and calibration. Hydrogen is used as both the carrier and FID fuel. An active chemical filter is placed in line with the hydrogen line to further reduce trace contaminants from the gas. About 25-microliters per minute is used. Use is continuous from the 30-cubic feet, 2000-psi cylinder used in the trial. This size provides about 2.5-weeks of use before replacement is required. A gas mixture containing 10 ppm of methyl ethyl ketone, 10-ppm of 1,1,1-trichloroethane with the balance of nitrogen is used to provide the calibration for the gas chromatograph. About 100-milliliters per minute for 6 minutes every 5 hours is used. The 30-cubic foot, 2000-psi cylinder used will provide about one year of service before replacement is required. Nitrogen is used, only in the laboratory tests, to verify the cleanliness between sampling runs. It was found to be unnecessary in the field trial. Stainless steel fittings and tubes are used to connect the subsystem to the air sampler subsystem. This subsystem was designed and built by SNL.

\section{Weather Station Subsystem}

A two level (height) meteorological station is used to obtain an indication of atmospheric mixing conditions. It consists of temperature, pressure, relative humidity, wind speed and direction sensors, and a computing data logger. One set of sensors is at 10-meter height and the other set is at 30-meters height. Data readi igs are taken every second, suitably averaged by the data logger to 1 minute intervals and then collected by the computer system every half hour. Communication between the weather station and the computer system is via an optoisolated RS232 interface cable. This subsystem was procured.

\section{Computer/Telecommunications Subsystem}

The computer used was an IBM PC-based system. The subsystem has the following components:

1. Intel 386 microprocessor, 387 math coprocessor, 4MB RAM, 80MB hard disk, 2 serial ports, 2 parallel ports, 102 enhanced keyboard, (SNL supplied)

2. HP Laserjet IIIP printer (SNL supplied)

3. US West Cellular telephone and MicroCom MicroPorte 1042 modems (procured)

4. Software: Peak2 for controlling the chromatograph and recording data, SuperKey for mimicking human key-stroke entries, Carbon Copy for communications, PeakFit 3 for post run analysis of chromatographs, Excel for creating summary results, and a SNL developed $\mathrm{C}$ program to administrate the runs. (all procured except C program)

The computer system controls all aspects of the ambient air monitoring system including events like temperature profiles, valving actions, etc. Data is recorded and stored by the system. 
The telecommunications units are to allow for remote access to information, and control of the measuring system.

\section{City Trailer Subsystem}

The mobile trailer provides a semi-clean, relatively temperature controlled environment for instruments. Its interior dimensions are $11.5 \times 7.5 \times 6.5$-feet (length $\times$ width $\times$ height). A laboratory type table top is present on two of the four walls. We set the built in thermostatically controlled heating unit so that the temperature in the trailer was about $84^{\circ} \mathrm{F}$. The trailer was provided by the City of Albuquerque. 


\section{Field Trial}

Following the laboratory setup and testing of the subsystems, two field trials were conducted: one at a SNL site (just north of the Tech Area III gate) and the second at the GE Aerospace site. The first trial was used to test interfaces to the City of Albuquerque trailer. We assured that the gas cylinders would fit in the space under the table top, that the environmental control in the trailer was sufficient for the laboratory designed gas chromatograph, that the cellular telephone would function for both voice and data transmission, that the weather station was operating, that our computer system could function with the weather station data logger, and that the software ran the system totally unattended. We also assured that the system would shutdown and re-start in a controlled manner in event of power outage.

\section{GE Site preparation}

The placement of the trailer was chosen by the 6612 meteorological team members and the GE personnel. The site chosen was on the northeast corner of the main plant building (just east of the GE credit union building.) The space allowed both the trailer and the weather station to be placed at sufficient distances from buildings and other air flow perturbing structures.

Additionally, the weather station was sitc such that if it collapsed, it would not fall on nearby power lines.

Figure 1 shows a schematic of the pertinent portion of the GE site. The (1) symbol in the upper right corner is the chosen trailer site. The weather station was just to the north of the trailer. The two heavy black $\bullet$ dots show the approximate stack emission points.

\section{Initial site setup}

The City of Albuquerque trailer was sited at GE on Wednesday 11/4/92. It was moved by SNL personnel on a flat bed trailer from the Tech Area III site to the GE site on south Broadway. GE facility personnel made the electrical power hook-up from a nearby building to the trailer power box on Thursday 11/5/92. We finished installing and testing the equipment on Friday 11/6/92 and performed the column cleaning operation over the weekend. Normal data runs began on Monday 11/9/92. 


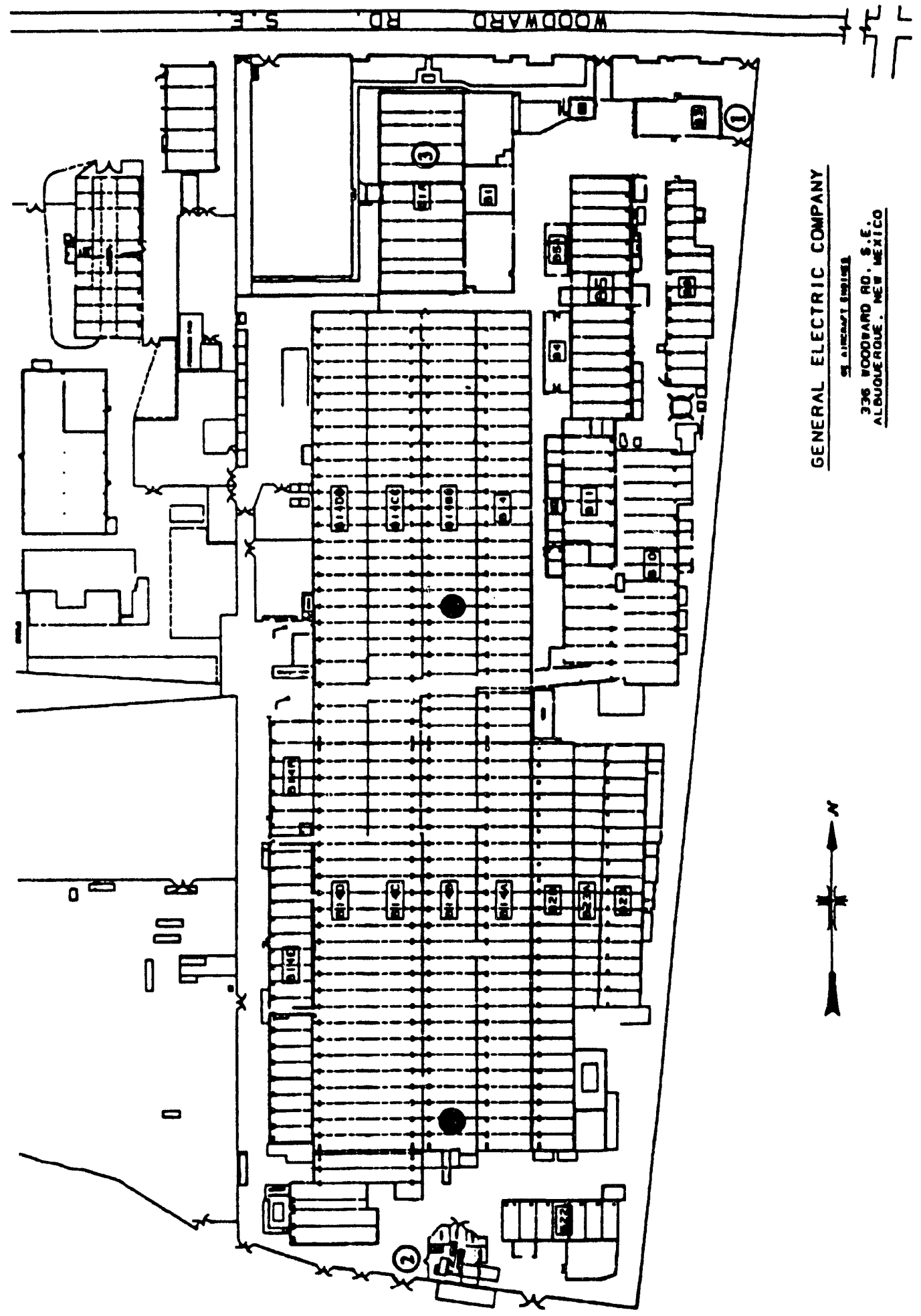

Figure 1. Schematic of GE site layout. 


\section{0 day tria! results}

The GE field trial had two major phases: a learning phase ( $\approx 3$-weeks) and the act ral field trial phase ( $\approx 3$-weeks). The learning phase spans the interval from $11 / 9$ to $11 / 23$ and the field trial phase spans the interval from $11 / 24$ to $12 / 22$. This separation is a consequence of the miscommunication about the chemicals in use at GE. Our laboratory testing determined that a column oven temperature of $55^{\circ} \mathrm{C}$ allowed for good separation between the two chemicals originally thought to be used at GE: MEK and 1,1,2-TCA. However, at this temperature the actual 1,1,1-TCA species output peak overlaps the MEK peak on the chromatographs. This prevents unambigucus chemical detection. After we resolved the issue, we lowered the column oven temperature to $40^{\circ} \mathrm{C}$ which provides good separation of the MEK and 1,1,1-TCA output peaks. However, the air sample data taken during this first phase cannot be used to determine how much MEK or 1,1,1-TCA is in the air. This does not detract from the point that the system instruments themselves performed as designed and operated totally unattended.

During the second phase, unambiguous results were obtained, i.e., we can make some statements about the chemicals detected in the air at the sampling position. Also, during this phase we decided to stop the system on Friday 12/4/92 due to the high winds being reported on the radio weather reports. We were concerned that the glass inlet tube (which extends about 1.5-yards from its tie point to the trailer) could snap off from the wind force. We then restarted the equipment on Monday 12/14/92.

\section{SUMMA ${ }^{\text {m }}$ Canister Sampling}

Verification of the presence of MEK and 1,1,1-TCA in the ambient air was obtained by taking SUMMA ${ }^{T M}$ canister air samples and having them analyzed by a certified laboratory. The SUMMA ${ }^{\mathrm{TM}}$ canisters are specially treated (passivated) stainless steel containers which arc an approved EPA technique for ambient air sampling for VOCs. The SUMMA ${ }^{\mathrm{TM}}$ canisters used for these tests were 15 liter size and were set to sample for approximately 24 hour periods. The canisters were procured from Radian Corporation of Austin, Texas and were returned to them for analysis.

The canisters were placed next to the trailer on the GE site at various times during the system field trials. According to GE, the MEK use is intermittent and occurs only during painting operations; while the 1,1,1-TCA is used as a degreaser and is used almost continuously during plant operating hours. Thus, the canister samples were taken during periods when the GE personnel had indicated they would be using both of the VOCs of interest. The canister and trailer locations relative to the positions of the emission sources are shown in Figure 1.

The SUMMA ${ }^{\mathrm{TM}}$ canister data is summarized in the table below. These data were taken over periods of approximately 24 hours and are, therefore, integral samples and not directly comparable to the data collected via the much shorter duration automated sampling method. (We show an average of the automated sampling method data collected for the 3 days of overlap with SUMMA ${ }^{7 M}$ data.) The usefulness of the canister data was primarily as a verification of the presence of the VOCs of interest. The data shown in the table indicates that both the MEK and the 111-TCA were consistently present at part per billion levels in the ambient background. Our results also show the same background presence of those VOCs, Figures 2-4. But, our data also show that there were some instances when the concentrations of these materials were significantly above the normal background and quite readily detectable. 
Our data also typically showed the presence of oiner, unidentified compounds, see Figure 4 and the discussion below. These unidertitied compounds are probably some of the compounds found by the Radian analysis as shown in the table below. We believe these are due to emissions from gasoline storage tanks. There are two sets of gasoline storage tanks in the general area of the GE plant, one is just east of the plant and the other is south of the plant, but considerably farther. It is interesting to note that the 1,1,2-TCA, which we mistakenly targeted as one of the compounds of interest early in the field trial, was not present at all; either in the canister data or our data. Since GE Joes not use that material and it is not usually found as a constituent in gasoline this result is not unexpected.

\section{Canister \# \\ Start: Date \\ Time \\ Stop: Date}

Compound

Methanol

Isopentane

Ethanol

Methyl t-Butyl Ether

2-Butanone (MEK)

1,1,1-Trichloroethane

(TCA)

Benzene

Isoheptane \& 2,3-

Dimethylpentane

2,2,4-Trimethylpentane

1,1,2-Trichloroethane

Toluene

Ethylbenzene

p- \& m-Xylene

o-Xylene

Isopropylbenzene

1,2,4-Trimethylbenzene
Table 1. Summa Canister results.

$\begin{array}{cccccc}1776 & 1907 & 1678 & 1827 & 1904 & 1694 \\ 11 / 12 / 92 & 11 / 16 / 92 & 11 / 17 / 92 & 12 / 2 / 92 & 12 / 16 / 92 & 12 / 17 / 92 \\ 14: 22 & 14: 38 & 14: 26 & 11: 14 & 11: 09 & 11: 05 \\ 11 / 13 / 92 & 11 / 17 / 92 & 11 / 18 / 92 & 12 / 3 / 92 & 12 / 17 / 92 & 12 / 18 / 92 \\ 15: 35 & 14: 20 & 14: 10 & 11: 55 & 11: 03 & 11: 44\end{array}$

Concentration (in ppbv)

$\begin{array}{rrrrrr}4.80 & 4.10 & 46.20 & 1.10 & 9.30 & 45.40 \\ 62.50 & 91.30 & 31.00 & 36.40 & 18.50 & 34.10 \\ 11.90 & 25.90 & 9.50 & 9.90 & 43.70 & 10.20 \\ 13.90 & 18.70 & \text { ND } & \text { ND } & \text { ND } & \text { ND } \\ 1.20 & 2.00 & 0.30 & 0.70 & 0.20 & 0.50 \\ & & & \{68\} & \{12\} & \{13\} \\ 0.80 & 1.70 & 230 & 2.60 & 5.50 & 8.20 \\ & & & \{28\} & \{6\} & \{20\} \\ 6.10 & 7.50 & 3.60 & 6.10 & 1.90 & 4.10 \\ 4.10 & 5.70 & 2.10 & 3.60 & 0.90 & 2.20 \\ & & & & & \\ 2.20 & 3.60 & 1.10 & 2.30 & 0.60 & 1.40 \\ \text { ND } & \text { ND } & \text { ND } & \text { ND } & \text { ND } & \text { ND } \\ 9.60 & 13.40 & 6.70 & 13.40 & 2.90 & 7.10 \\ 1.30 & 1.90 & 0.80 & 1.70 & 0.40 & 0.90 \\ 3.50 & 5.30 & 2.40 & 5.20 & 1.00 & 2.70 \\ 1.10 & 1.70 & 0.70 & 1.60 & 0.30 & 0.80 \\ \text { ND } & 0.20 & \text { ND } & 0.09 & \text { ND } & \text { ND } \\ 0.70 & 1.90 & 0.70 & 1.90 & 0.30 & 1.20\end{array}$

Site closedown

The equipment was turned off on Tuesday 12/22/92. The computer system and the weather station were returned to SNL, and the calibration gases were returned to the vendor. The remainder of the equipment as well as the City of Albuquerque trailer were released to the City on Wednesday 12/23/92. 


\section{Conclusions and Recommendations}

\section{Site emission status}

At present there does not appear to be regulatory levels on the concentrations allowable at exterior positions (i.e., outdoors/pubic ambient air) to industrial sites. The regulations only place limits on the mass weight per hour of the chemicals emitted into the air. However, at least two states (Texas and California) are using the following rule of thumb for allowable concentrations in public outdoor air space: one one-hundredth $(1 / 100)$ the TLV-TWA level for each chemical species. The values for the chemicals we were concerned with are shown below:

\begin{tabular}{|c|c|c|}
\hline Chemical & TLV-TWA & Ambient air limit \\
\hline MEK & $200 \mathrm{ppm}$ & $2 \mathrm{ppm}$ \\
\hline ill-TCA & $350 \mathrm{ppm}$ & $3.5 \mathrm{ppm}$ \\
\hline
\end{tabular}

The data taken during the second phase (11/24 to 12/22) is shown in Figures $2-4$. The plots present data readings in ppm of the two chemicals on the $y$-axis and time of reading on the $x$ axis. The presentation is grouped by weeks, with the major time divisions being days of the week, starting on a Monday and ending on a Sunday. Each data point is a 6-minute air sample and each data point is (nominally) every half hour. As is seen, the data readings are usually much smaller than the above ambient air limit. However, there is are a few time spans where the readings are significant. That is of the order of several hundred $\mathrm{ppb}$.

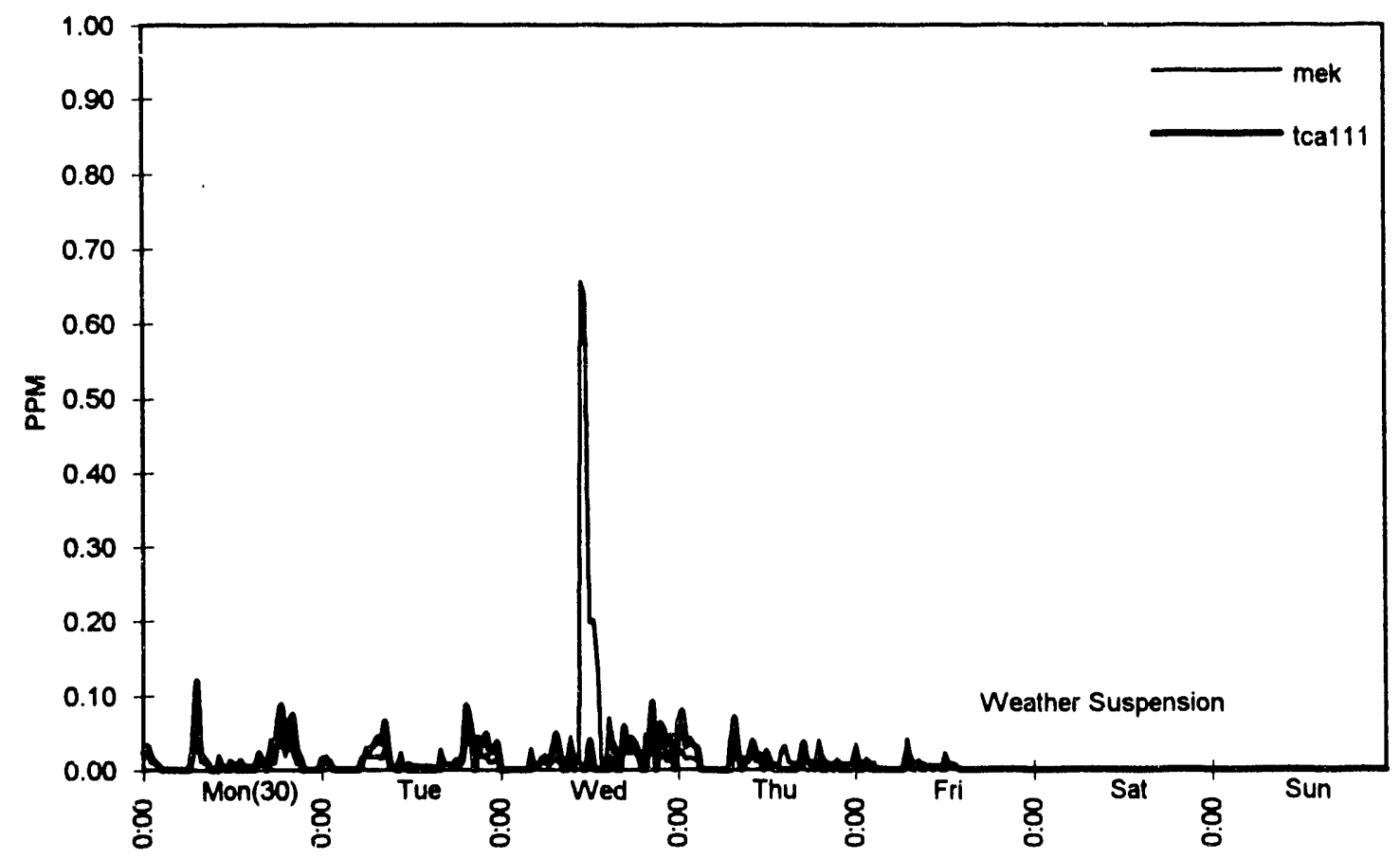

Figure 2. Air sample effluents during week of Nov 30 to Dec 6 


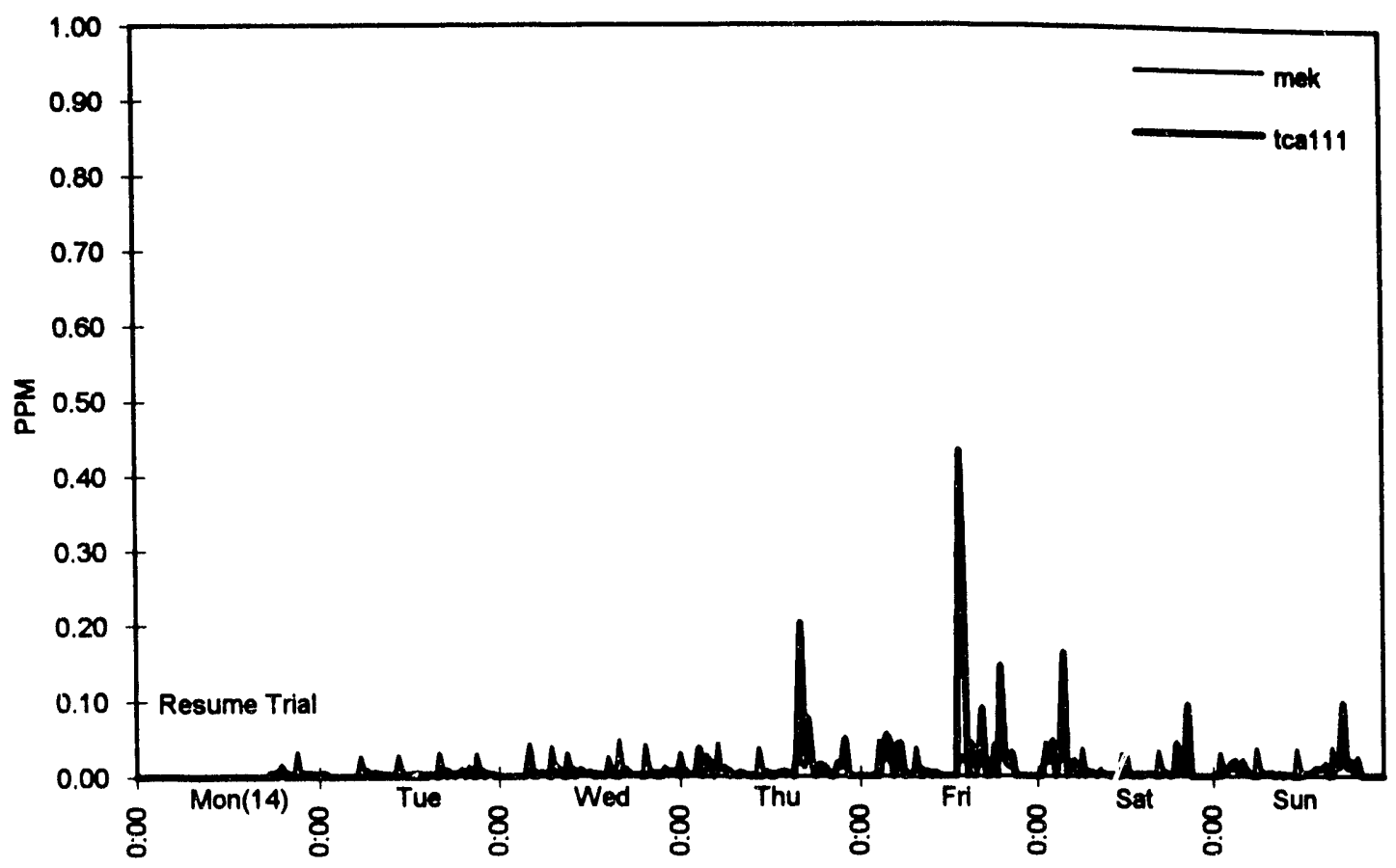

Figure 3. Air sample effluents during week of Dec 14 to Dec 20

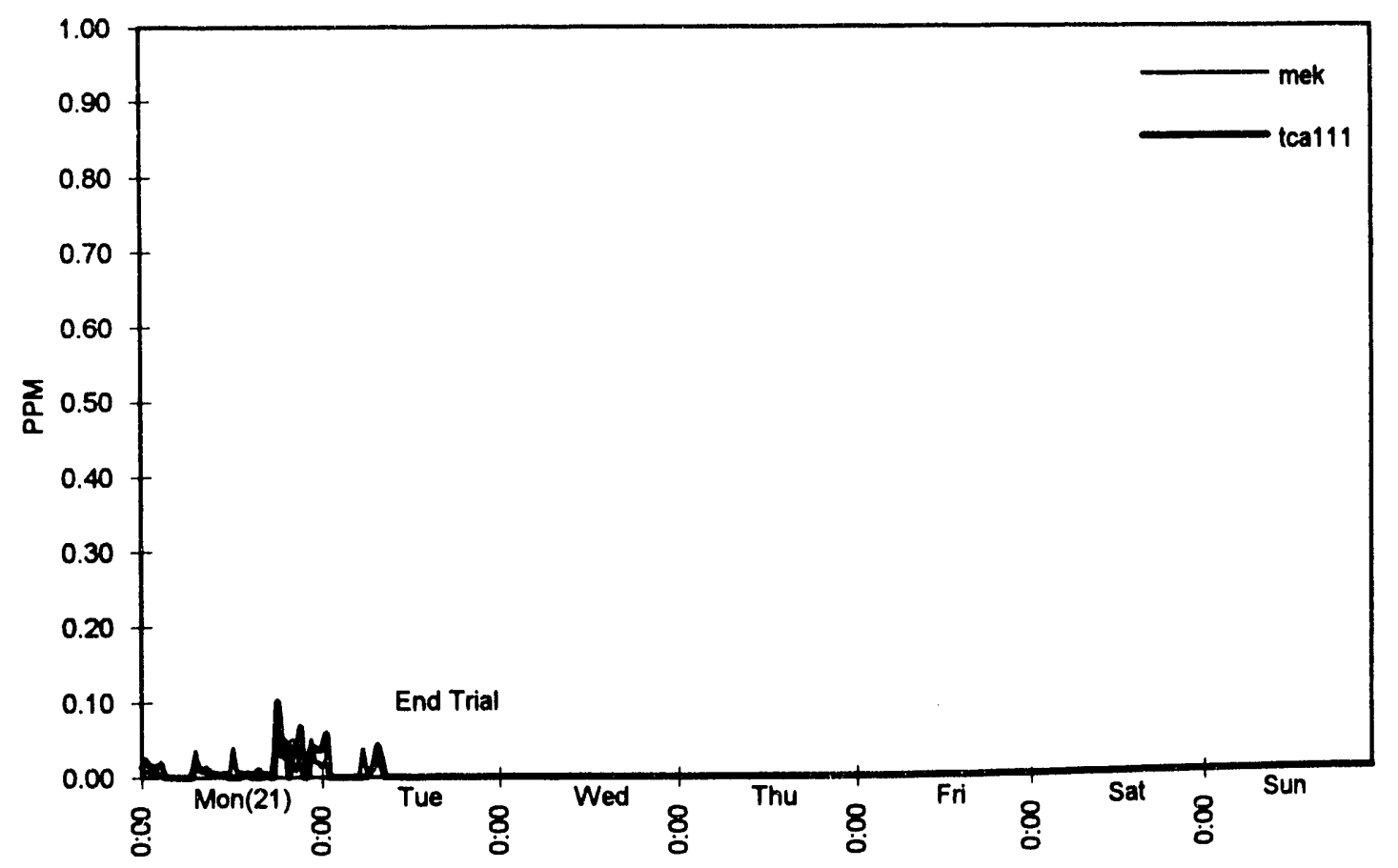

Figure 4. Air sample effluents during week of Dec 21 to Dec 27 


\section{Instrument suitability}

The major instrument of the system was the SRI gas chromatograph. Its suitability can be measured by: a) its minimum detection limit, b) it state of automation, and c) its use as a field instrument. The issue of suitability also needs to be taken in context. The context of the goals of the study (a quick look at existing instrumentation) and the context of what improvements could be made from a deisigner's perspective.

For the two chemicals of interest in the current study, the detection limit was about 10-20 ppb. Since the rule of thumb for MEK and 111-TCA gives a required limit of 2-3 ppm, this instrument is suitable from the detectibility measure. No significant (easily done) improvements can be seen from a design perspective.

From the results of the study, the GC has an appropriate level of automation. Setting column oven temperature, controlling the trap heating/cooling state, and controlling the load/inject valve are all under electronic control. However, from the design perspective its almost complete lack of state of health monitoring, such as, the flow rate through the column, the temperature of the oven, the temperature of the trap, the pressure at various points in the instrument, and so on could be considerably improved.

Its use as a field instrument concerns its ruggedness for the environment it will be used in. In the current study, the environment was quite benign, essentially a laboratory environment as provided by the trailer subsystem. The temperature was controlled to within a $5^{\circ} \mathrm{F}$ range with a median of about $84^{\circ} \mathrm{F}$, and it was placed in a relatively dust free environment. During our SNL field trial, we observed that dust entered the trailer quite easily. Dust entering the FID chimney, or the computer system disk drives could easily cause a malfunction. It certainly was semi-portable, however it was a bulky instrument that required about 4 hours to set up.

Adding the air sampling plumbing increased the bulkiness. Again, from the present study perspective, the instrument has an adequate state of ruggedness. From a design perspective, it could be repackaged and thus be considerably more rugged. We believe that the entire system (excluding the weather station) could be repackaged into a volume similar to the current vol:me of the SRI gas chromatograph itself.

In summary, per the goals of the study, (limited 30 day trial), the main detecting instrument used performed quite well. Its long term (i.e., on the order of a year) performance is unknown. The main point is the lack of state of health measurements of the important instrument properties.

\section{Recommendations for future work}

The table below compares our goals to our performance

\begin{tabular}{|r|l|l|}
\hline & \multicolumn{1}{|c|}{ Goal } & \multicolumn{1}{c|}{ State } \\
\hline 1. & $\begin{array}{l}\text { automatic operation (no } \\
\text { operator intervention except } \\
\text { for periodic maintenance and } \\
\text { data interrogation) }\end{array}$ & $\begin{array}{l}\text { The system is completely automatic. Maintenance } \\
\text { was about every 20 days to replenish the hydrogen } \\
\text { cylinders. Other maintenance items are probably } \\
\text { on the several month time scale. }\end{array}$ \\
\hline 2. & self-calibrating & $\begin{array}{l}\text { The system performed calibration on a regular } \\
\text { basis automatically. }\end{array}$ \\
\hline
\end{tabular}




\begin{tabular}{|c|c|c|}
\hline 3. & self-cleaning & $\begin{array}{l}\text { The system performed column and trap bake-outs } \\
\text { automatically. }\end{array}$ \\
\hline 4. & $\begin{array}{l}\text { semi-portable (movable by } \\
\text { single person, placeable in } \\
\text { temperature controlled trailer) }\end{array}$ & $\begin{array}{l}\text { The system was semi-portable. It was placed in a } \\
\text { mobile trailer. }\end{array}$ \\
\hline 5. & $\begin{array}{l}\text { real-time operation (all } \\
\text { analysis performed on site) }\end{array}$ & $\begin{array}{l}\text { We did not implement this function. The data was } \\
\text { reduced after the fact using commercial software. }\end{array}$ \\
\hline 6. & $\begin{array}{l}\text { air sampling duty cycle as } \\
\text { rapid as possible }\end{array}$ & $\begin{array}{l}\text { Air samples were taken every half hour for a six } \\
\text { minute period. }\end{array}$ \\
\hline 7. & $\begin{array}{l}\text { coordinated with } \\
\text { meteorological data }\end{array}$ & $\begin{array}{l}\text { A meteorological tower with automatic data } \\
\text { recording was connected to the computer system } \\
\text { and data was stored in time dated files. The } \\
\text { chromatographs were also stored in time dated files } \\
\text { so the coordination could be accomplished. }\end{array}$ \\
\hline 8. & communicate remotely & $\begin{array}{l}\text { A cellular telephone, modem and } \\
\text { telecommunication software were used during the } \\
\text { field trial. Some problems still remain to be } \\
\text { resolved. }\end{array}$ \\
\hline 9. & $\begin{array}{l}\text { low maintenance (replaceable } \\
\text { filters, replaceable gas } \\
\text { cylinders, etc.) }\end{array}$ & $\begin{array}{l}\text { Replacement of the gas cylinders was the only } \\
\text { maintenance operation required during the field } \\
\text { trial. It was accomplished in less than } 1 / 2 \text { hour. }\end{array}$ \\
\hline 10 & low instrument cost & $\begin{array}{l}\text { Total instrument cost excluding the weather station } \\
\text { was about } \$ 20,000 \text {. }\end{array}$ \\
\hline
\end{tabular}

The areas for future work should be in areas to increase the system state of health monitoring capability, to reduce the system bulkiness, to increase the number of chemical species detectable, to provide for more continous readings, and to develop software for automatic data reduction. System monitoring of the various temperature, pressure, and electrical parameters are necessary for true unattended operation and for data quality assurance. System bulkiness could be easily reduced. We could combine both the SRI chromatograph and the air sampling components into the same volume as the SRI chromatograph has at present. Additionally, using the rule of thumb of using TLV-TWA based limits, we could configure a system based upon using TLV-STEL values. This means we could provide outputs every 15-minutes as dictated by the TLV-STEL requirements which is the common understandable measure for compliance evaluation. 


\section{Appendices}

\section{A. Definition of Terms}

Here is a short list of the common terms used in this report.

\begin{tabular}{|c|c|}
\hline Term & Definition \\
\hline 111-TCA & $\begin{array}{l}\text { trichloroethane } 1,1,1 \text { : proper chemical name is } 1,1,1 \text {-tri- } \\
\text { chloroethane; chemical formula is } \mathrm{CH}_{3} \mathrm{CCl}_{3} \text {. Some of its } \\
\text { chemical properties are: } \\
\begin{array}{ll}\text { molecular weight } & 133.41 \\
\text { melting point } & -33^{\circ} \mathrm{C} \\
\text { boiling point } & 74^{\circ} \mathrm{C} \\
\text { density } & 1.3492\end{array}\end{array}$ \\
\hline $112-\mathrm{TCA}$ & $\begin{array}{l}\text { trichloroethane } 1,1,2: \text { proper chemical name is } 1,1,2 \text {-tri- } \\
\text { chloroethane; chemical formula is } \mathrm{Cl}_{2} \mathrm{CHCH}_{2} \mathrm{Cl} \text {. Some of its } \\
\text { chemical properties are: } \\
\begin{array}{ll}\text { molecular weight } & 133.41 \\
\text { melting point } & -37.4^{\circ} \mathrm{C} \\
\text { boiling point } & 113^{\circ} \mathrm{C} \\
\text { density } & 1.4405 \\
\end{array}\end{array}$ \\
\hline CAA, CAAA & Clean Air Act, Clean Air Act Amendments \\
\hline EPA & United States Environmental Protection Agency \\
\hline MEK & 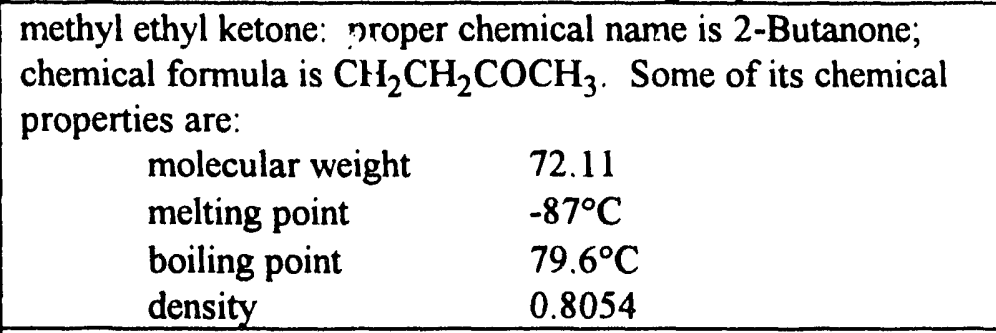 \\
\hline $\mathrm{ppb}$ & $\begin{array}{l}\text { parts per billion. This term can vary in definition according to } \\
\text { the topic being discussed. For our purposes it will mean } \\
\text { volume fraction of the sample analyzed. }\end{array}$ \\
\hline ppm & $\begin{array}{l}\text { parts per million: This term can vary in definition according to } \\
\text { the topic being discussed. For our purposes it will mean } \\
\text { volume fraction of the sample analyzed. }\end{array}$ \\
\hline TLV-STEL & $\begin{array}{l}\text { Threshold Limit Value-Short Term Exposure Limit. A 15- } \\
\text { minute TWA exposure which should not be exceeded at any } \\
\text { time during a workday even if the 8-hour TWA is within the } \\
\text { TLV-TWA. }\end{array}$ \\
\hline TLV-TWA & $\begin{array}{l}\text { Threshold Limit Value-Time Weighted Average. Defined by } \\
\text { the American Conference of Governmental Industrial } \\
\text { Hygienists as the time-wieghted average concentration for a } \\
\text { normal } 8 \text {-hour day and a } 40 \text {-hour workweek to which nearly all } \\
\text { workers may be repeatedly exposed, day after day, without } \\
\text { adverse effect. }\end{array}$ \\
\hline
\end{tabular}




\begin{tabular}{|l|l|}
\hline trap & $\begin{array}{l}\text { an activated carbon powder placed in a stainless steel tube 'Ised } \\
\text { to adsorb the VOCs of interest during the collection sequence. }\end{array}$ \\
\hline $\begin{array}{l}\text { volatile organic compound } \\
\text { (VOC) }\end{array}$ & $\begin{array}{l}\text { carbon containing chemical species with significant vapor } \\
\text { pressure at room temperature. }\end{array}$ \\
\hline
\end{tabular}

\section{B. Typical Data Output}

\section{Chromatographs}

Figure 5 below combines two raw chromatographs taken on Wednesday 12/2/93 at 10:30 (thick trace) and 11:00am (thin trace). Most of the data runs appear like the 10:30 run. (Note the scale difference between the two traces). This data run admits of no clear cut conclusion as to the presence of the two chemicals of interest.

Reading the chromatogram consists of finding peaks in the trace, then measuring the peak time and the area under the peak. The peak times identify the chemical species; the area under the curve is related to the quantity of the chemical species. The measured MEK peak time is $11.244 \pm 0.192$-minutes (tolerance is for the $3 \sigma$ time). This peak is clearly evident in the 11:00 run. The measured 111-TCA peak time is $12.241 \pm 0.168$-minutes. The other peak times represent unidentified chemical species.

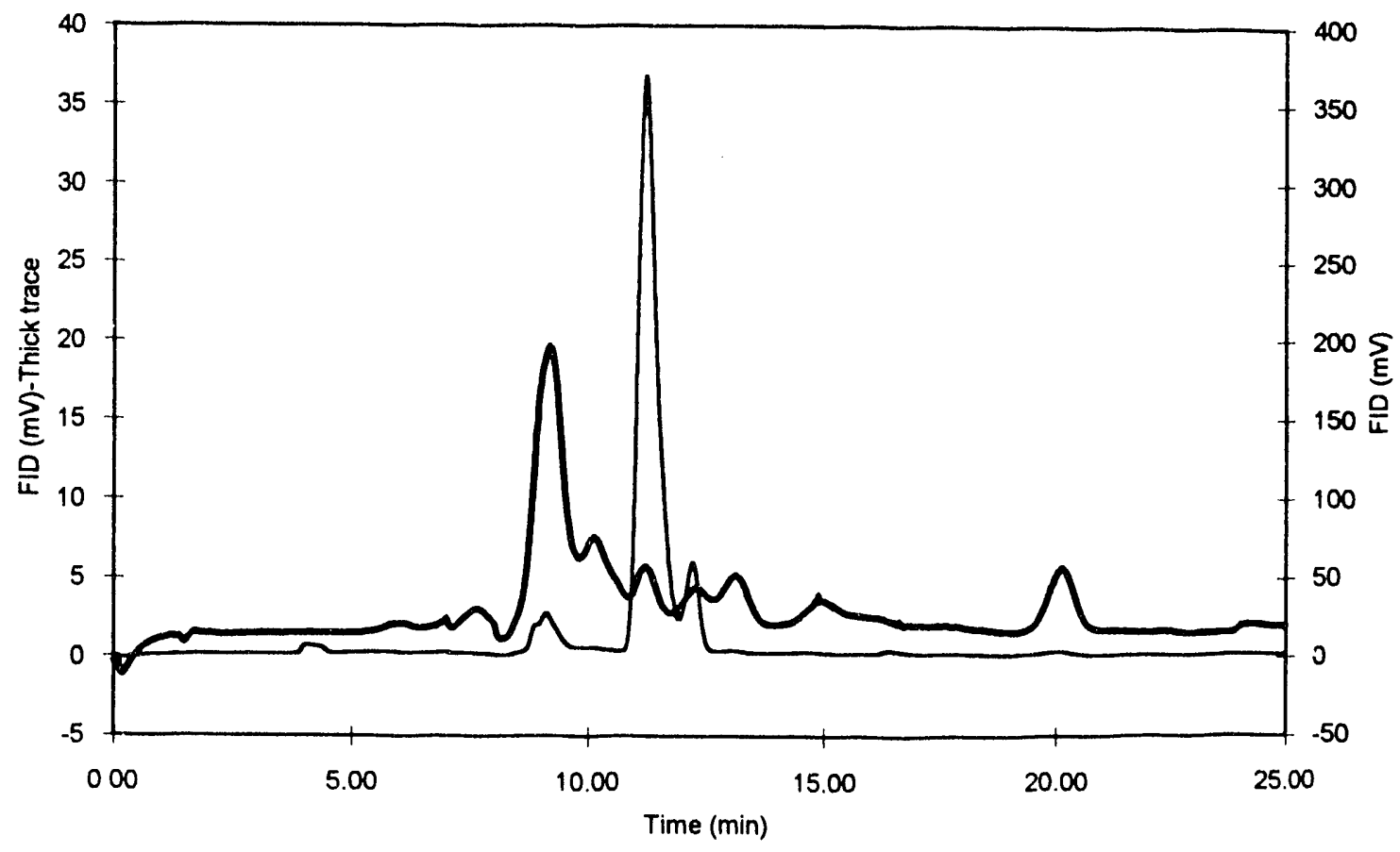

Figure 5. Chromatographs taken on Wednesday 12/2/93.

\section{Day Results}

Analyzing these chromatographs for each day produces data as shown in Figure 6. The data is plotted on a logarithmic graph. The use of the activated carbon trap places a lower limit of detectability at about 10 to 20-ppb. That is the peaks for MEK and 1,1,1-TCA are unambiguously resolved and larger than the peaks occuring just after calibration runs. 


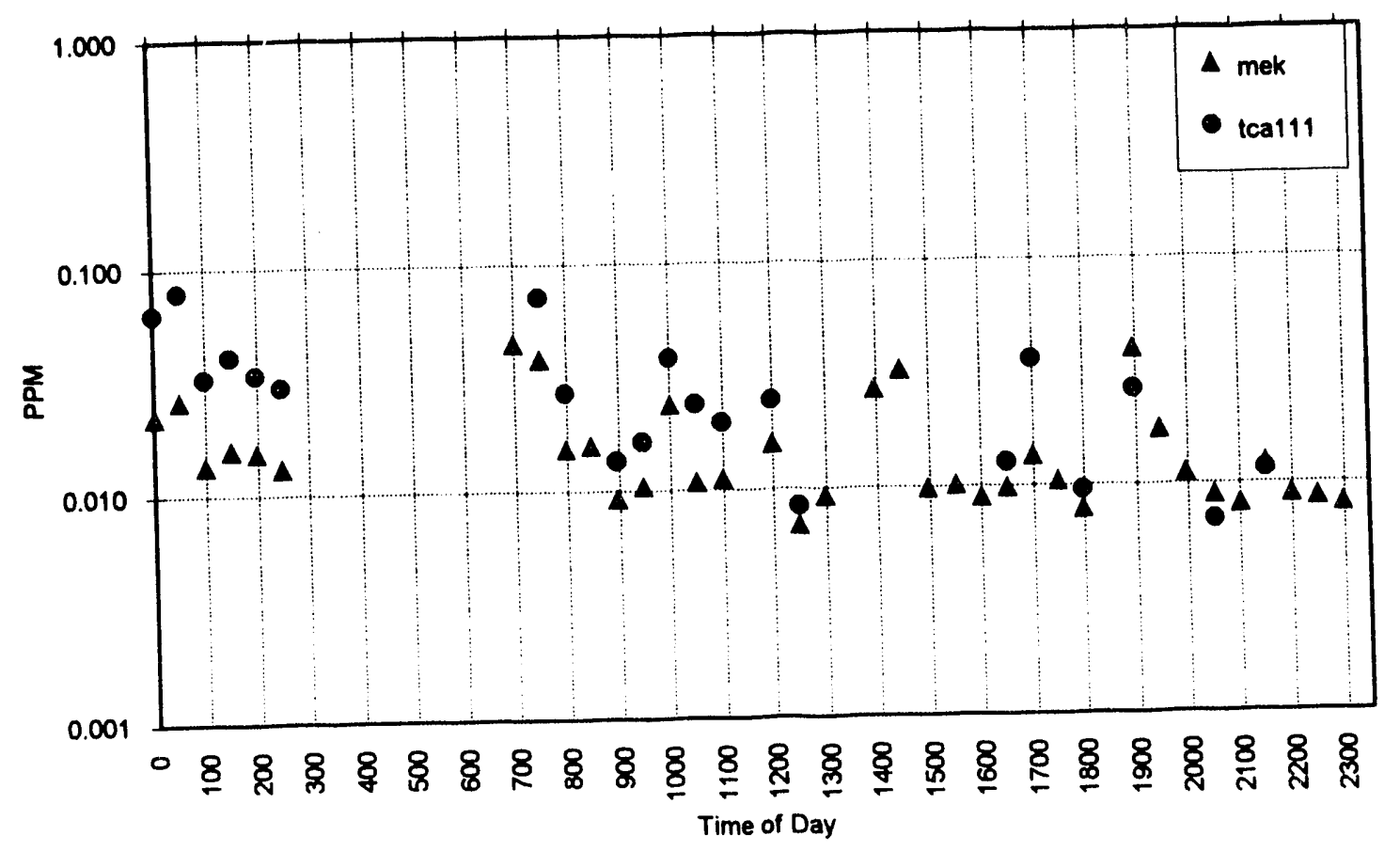

Figure 6. Typical results collected on a single day (12/3/93).

\section{Calibration Results}

The figures below show the calibration results for the time period from $11 / 23$ to $12 / 22$. Figure 7 shows the area under the curve for both MEK and 111-TCA. Each of these areas are set to correspond to 10-ppm which is the NIST traceable value quoted by the gas supplier. The only available data for the 111-TCA consists of the last three calibration runs of the trial. As is seen, the scatter about the mean is about $3 \%$ (for one standard deviation) for the MEK. This result shows that we could reduce the calibration run to once a day and thereby increase the number of ambient air samples. This would decrease the likelihood of missing a short term effluent value. Figure 8 shows the peak times for these two chemicals. Again this figure confirms the repeatability of the calibration runs. 


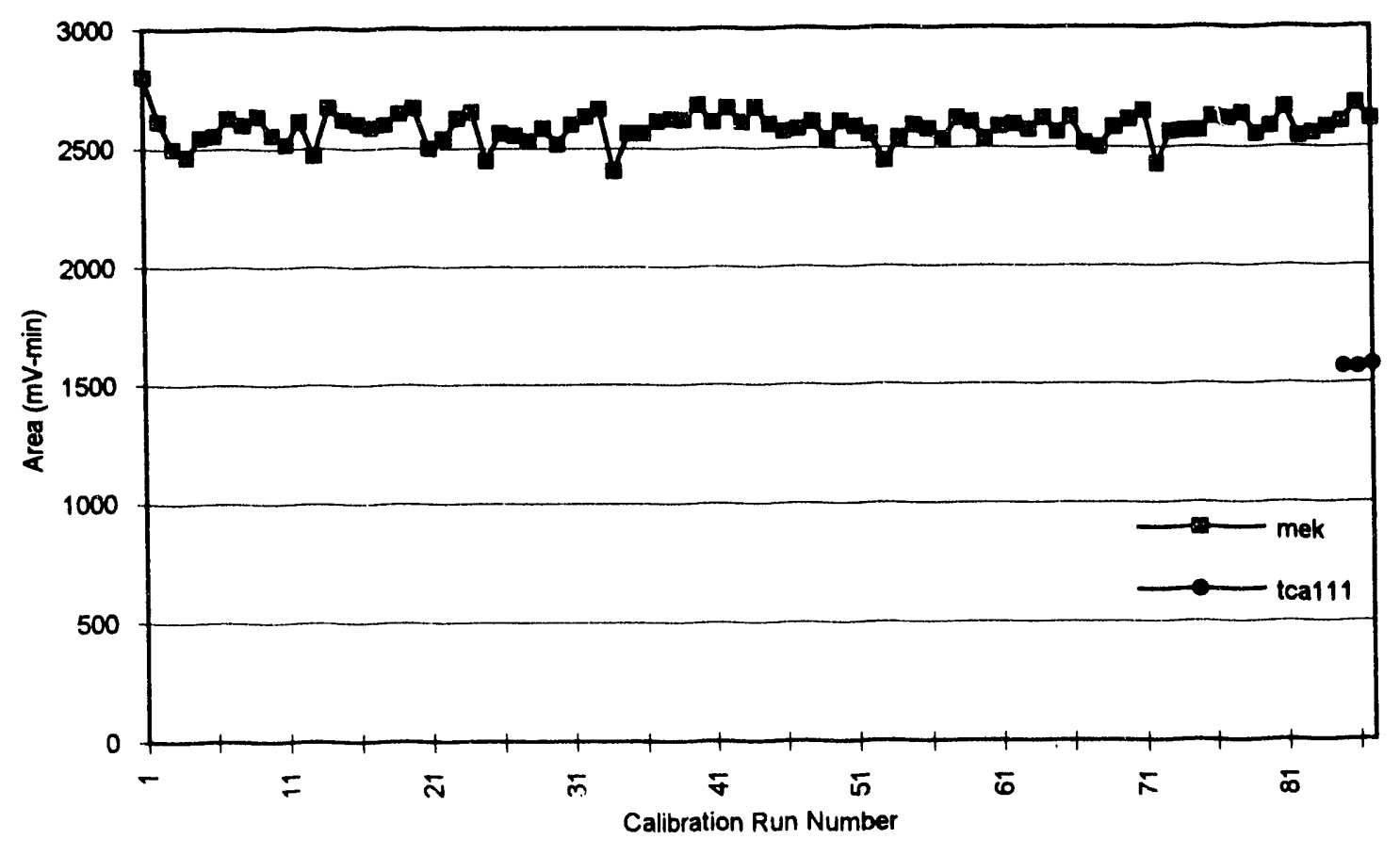

Figure 7. Calibration areas for MEK and 111-TCA for the 11/23 to 12/22 time period.

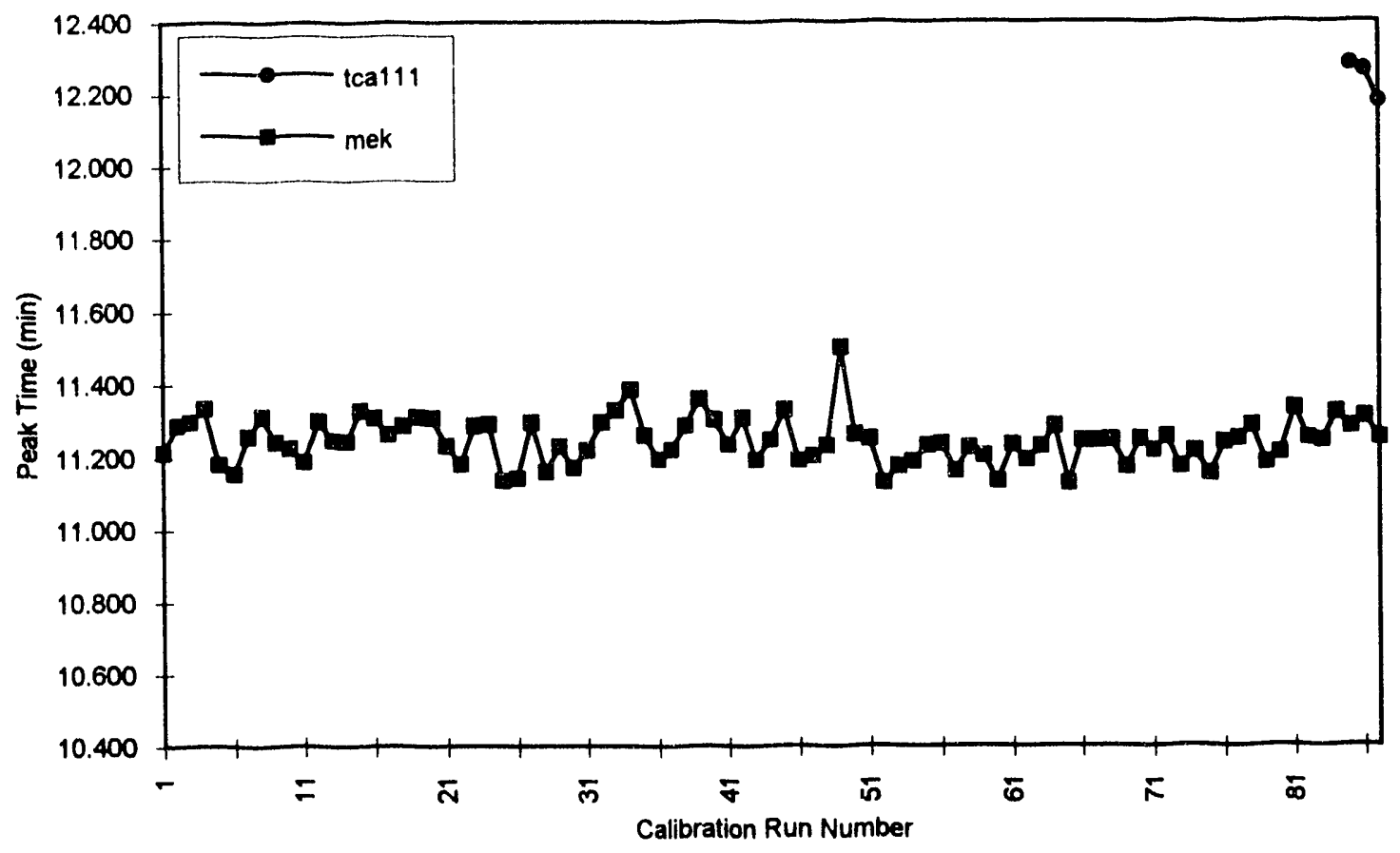

Figure 8. Calibration peak times for MEK and 111-TCA for the 11/23 to 12/22 time period. 


\section{Parts List}

Commercially procured parts

The items listed below were either purchased specifically for this project or were available as general SNL laboratory equipment.

\begin{tabular}{|c|c|}
\hline Description & Model Number \\
\hline Jas Chromatograph Subsystem & All Buck Scientific Model numbers \\
\hline Gas Chromatograph & Model 8610 \\
\hline EPA Method 624 Column & Model B8600-WBC 5 \\
\hline Purge \& Trap Assembly & Model B8690-0051 \\
\hline Flame-Ionization Detector (FID) & Model 8690-0010 \\
\hline Photo-Ionization Detector (PID) & Model 8690-0040 \\
\hline Interface card & part of Model 8610 \\
\hline Activated coconut charcol & Supelco, special order \\
\hline Weather Station Subsystem & All Campbell Scientific Model numbers \\
\hline Control Module & CR10 \\
\hline Enclosure, $12^{\prime \prime} \times 14^{\prime \prime}$ & ENC $12 / 14$ \\
\hline 12 V Power Supply & PS12LA \\
\hline Opto-isolated RS-232 Interface & SC32A \\
\hline Wind Speed Sensor, $11 \mathrm{ft}$ lead & $014 \mathrm{~A}$ \\
\hline Wind Speed Sensor, $34 \mathrm{ft}$ lead & $014 \mathrm{~A}-\mathrm{U}$ \\
\hline Nurail Connector for 014 & 1017 \\
\hline Crossarm Sensor Mount & $019 \mathrm{ALU}$ \\
\hline W Direction Sensor, $11 \mathrm{ft}$ lead & $024 \mathrm{~A}$ \\
\hline W Direction Sensor, $34 \mathrm{ft}$ lead & $024 \mathrm{~A}-\mathrm{U}$ \\
\hline Nurail Connector for 024 & 1049 \\
\hline Tower Mounting Bracket & UT018 \\
\hline Wind Sensor Bracket & 6880 \\
\hline Temperature Sensor, $34 \mathrm{ft}$ lead & 107-L34 \\
\hline Radiation Shield for 107 & 41301 \\
\hline Temp + Rel Humidity, $9 \mathrm{ft}$ lead & HMP-35C-U \\
\hline Radiation Shield for HMP35C & 41002 \\
\hline Barometer (600-1060 mbar) & PTA427A \\
\hline 10 Meter Tower + Mast & UT930 \\
\hline Tower Roof Mounting Base & RFM18 \\
\hline Duckbill Anchors & UTDUK \\
\hline Eyebolt Anchors & UTEYE \\
\hline Tower Guy Wire Kit & UTGUY \\
\hline Tower Grounding Kit & UTGND \\
\hline Datalogger Software (3.5" disk) & PC208-3 \\
\hline Graphics Software (3.5" disk) & PC210-3 \\
\hline \multicolumn{2}{|l|}{ Gas Subsystem } \\
\hline Hydrogen, UHP, $99.999 \%$ & Tri-Gas \#SGUHPHY3M \\
\hline $\begin{array}{l}\text { Calibration mixture, 10ppm MEK/111- } \\
\text { TCA, Nitrogen }\end{array}$ & Scott Specialty Gas, special order \\
\hline
\end{tabular}




\begin{tabular}{|l|l|}
\hline Pressure regulator 2 stage & Tri-gas \#432-3301 \\
\hline Bellow valve & Nupro \#SS-4BG-V51 \\
\hline Pressure relief/bleed valve & \#SS-RL3M4-S4-MO-100 \\
\hline Excess flow valve w/manual reset & \#6L-E4-HF-580-VR4 \\
\hline Air Sampling Subsystem & \\
\hline 2 micron particle filter & Nupro \#SS-4TF-2 \\
\hline Air pump & Barnant \#400-1901 \\
\hline Mass flow controller & Tylan \#FC260 \\
\hline $\begin{array}{l}\text { Control/Readout box for Mass flow } \\
\text { controller }\end{array}$ & Tylan RO-28 \\
\hline Switching valve, 6 port, multiposition & Valco \#ESF6P \\
\hline $\begin{array}{l}\text { Misc stainless steel tubing, Swaglock \& } \\
\text { VCR fittings }\end{array}$ & \\
\hline Computer/Telecommunications Subsystem & \\
\hline IBM/DOS PC & HP Vectra 386/25 \\
\hline Removeable disk drive & IOMEGA Bernoulli Dual 44 \\
\hline VGA monitor & \\
\hline Printer & HP LaserJet IIIP \\
\hline Line stabilizer/conditioner & Tripp Lite \#LC1800 \\
\hline Modem and software & MicroCom MicroPort 1042 \\
\hline Cellular telephone & Telular \#CPTE-1 \\
\hline
\end{tabular}

\section{Fabricated parts}

All of the items listed below were fabricated in the SNL shops.

1. Aluminum baseplate

2. Plexiglass shield

\section{System Design Intent}

The design intent inherent in the various subsysteins is discussed below. This appendix is not intended to be all inclusive, but instead to surnmarize our technical goals and our reasons for the specific implementation of this system.

\section{Summary of Operation}

The system can be in any of the following states listed below.

- reset position

- bakeout

- cal gas sample

- ambient air sample

- zero air sample

- inject (desorb) onto column

- cool down

Some properties of each of these states is described below. 
Purpose: the state that the system is reset to after turn-on or while waiting for another operation.

Settings: $\quad$ Stream select valve $=$ position 1 (vacuum)

trap valve $=$ load

trap heater $=$ OFF

oven temperature $=40^{\circ} \mathrm{C}$

pump $=\mathbf{O N}$

Bakeout

mass flow controller $=100 \mathrm{cc} / \mathrm{min}$

Purpose: $\quad$ trap \& column bakeout to remove residuai contamination

Settings:

Stream select valve $=$ position 1 (vacuum)

trap valve $=$ load

trap heater $=\mathrm{ON}\left(\right.$ setpoint $\left.=250^{\circ} \mathrm{C}\right)$

oven temperature $=250^{\circ} \mathrm{C}$

pump $=\mathbf{O N}$

Cal Gas Sample

Purpose:

mass flow controller $=100 \mathrm{cc} / \mathrm{min}$

Settings:

Ambient Air Sample

Purpose:

Settings:

\section{Zero Air Sample}

Purpose:

to concentrate vapors from a metered volume of cal gas onto the sorbent trap.

Stream select valve $=$ position $2(\mathrm{cal}$ gas $)$

trap valve $=$ load

trap heater $=\mathbf{O F F}$

oven temperature $=40^{\circ} \mathrm{C}$

pump $=\mathbf{O N}$

mass flow controller $=100 \mathrm{cc} / \mathrm{min}$

to concentrate VOC vapors from a metered volume of air onto the sorbent trap

Stream select valve to position 4 (ambient air)

trap valve to load position

trap heater $=$ off

oven temperature $=40^{\circ} \mathrm{C}$

pump $=\mathbf{O N}$

mass flow controller $=100 \mathrm{cc} / \mathrm{min}$

to concentrate a metered volume of zero air (dry nitrogen) onto the sorbent trap.

Settings: $\quad$ Stream select valve to position $3\left(\mathrm{~N}_{2}\right)$

trap valve to load

trap heater $=\mathbf{O F F}$

oven temperature $=40^{\circ} \mathrm{C}$

pump $=\mathbf{O N}$

mass flow controller $=100 \mathrm{cc} / \mathrm{min}$ 
Inject (desorb) onto column

Purpose:

to thermally desorb VOCs captured in sorbent trap (from whatever source) onto the GC column, separate them on the column, and detect them with the FID

Settings: $\quad$ Stream select valve $=$ position $\mathbf{X}$ (previous state)

trap valve $=$ inject

trap heater $=\mathrm{ON}\left(250^{\circ} \mathrm{C}\right.$ setpoint $)$

oven temperature $=40^{\circ} \mathrm{C}$

pump $=\mathbf{O N}$

mass flow controller $=100 \mathrm{cc} / \mathrm{min}$

Valve position drawings of all the above states are shown in Figures 9 to 14 .

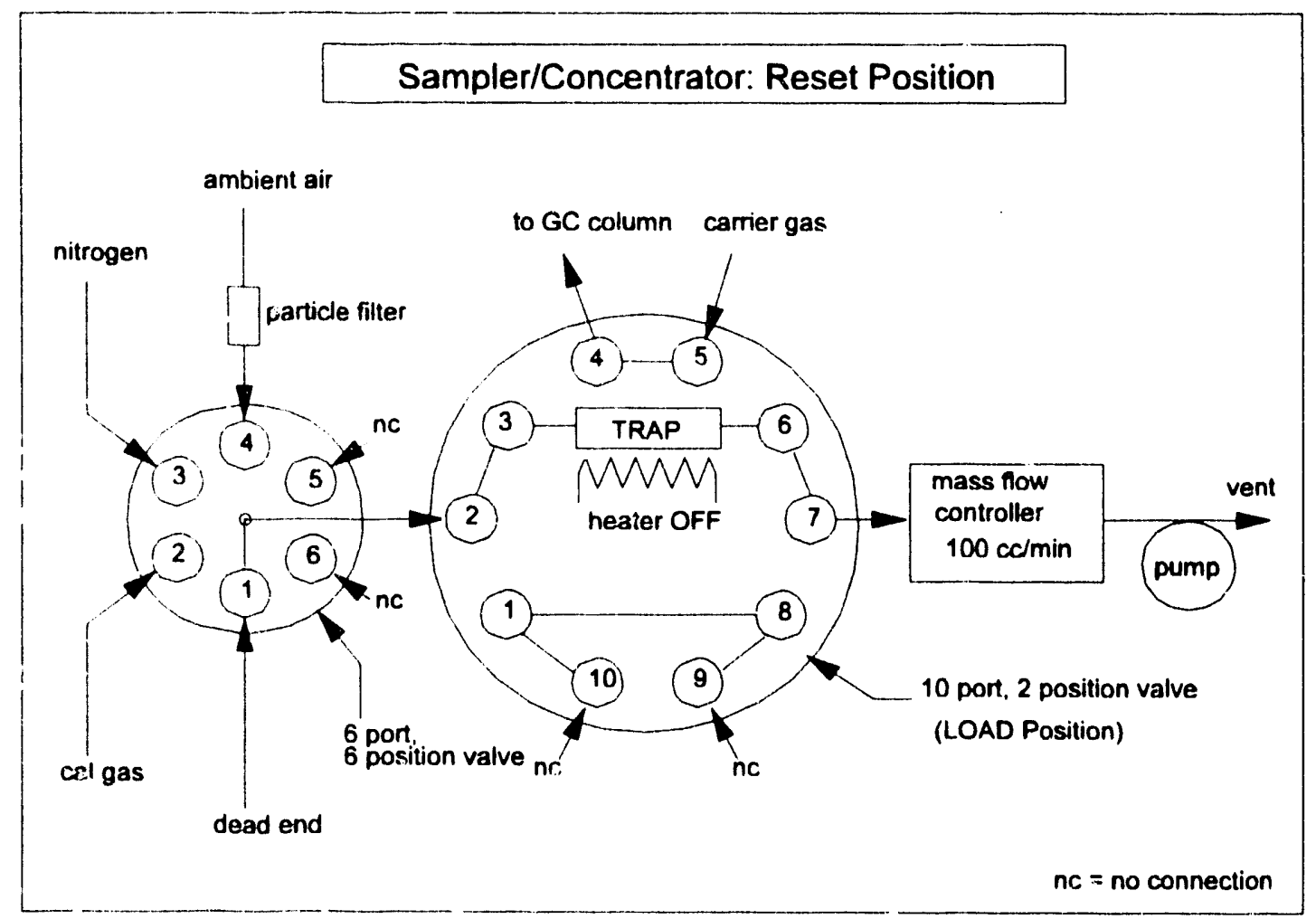

Figure 9. Valve position for reset state. 


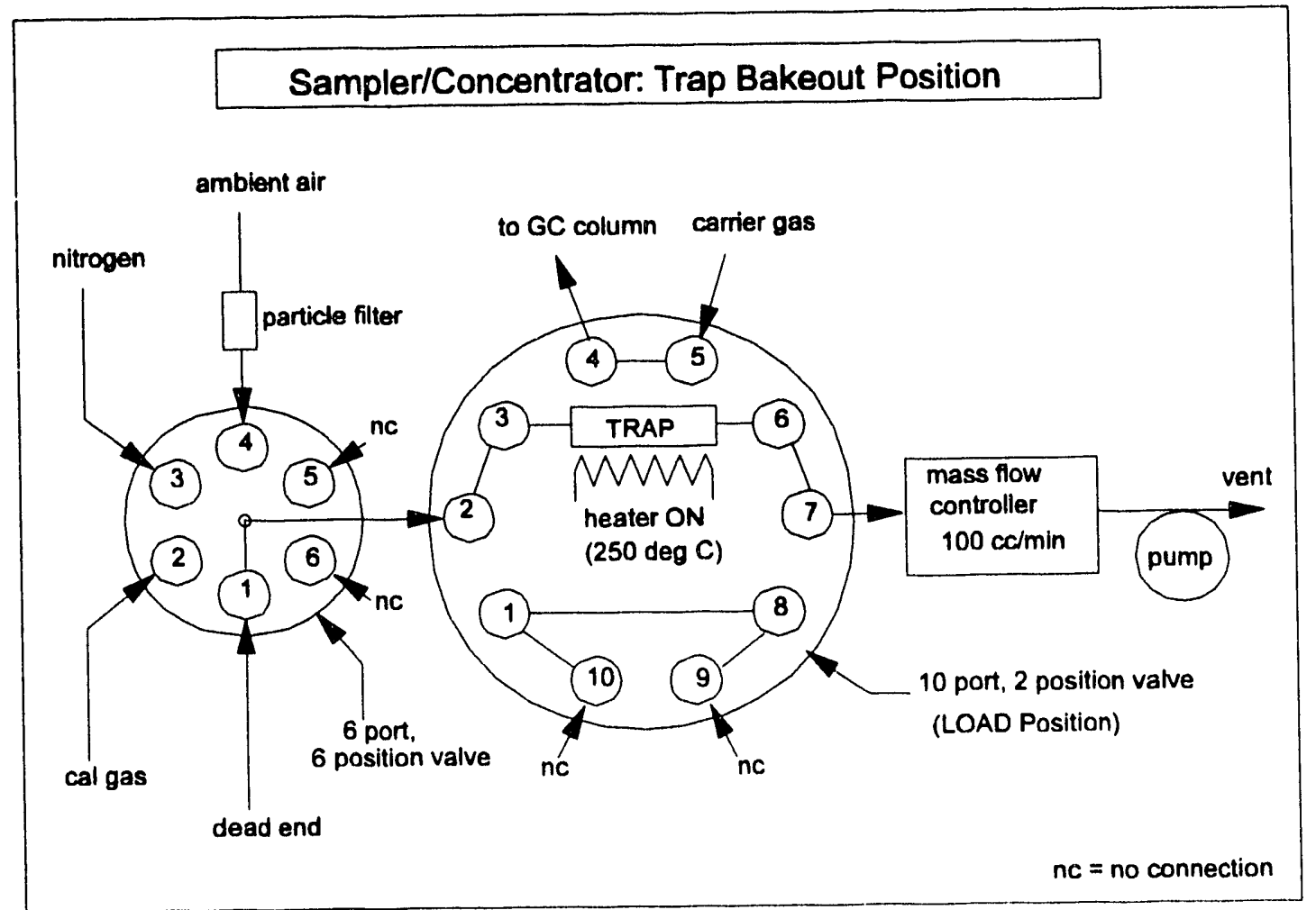

Figure 10. Valve position for bakeout state.

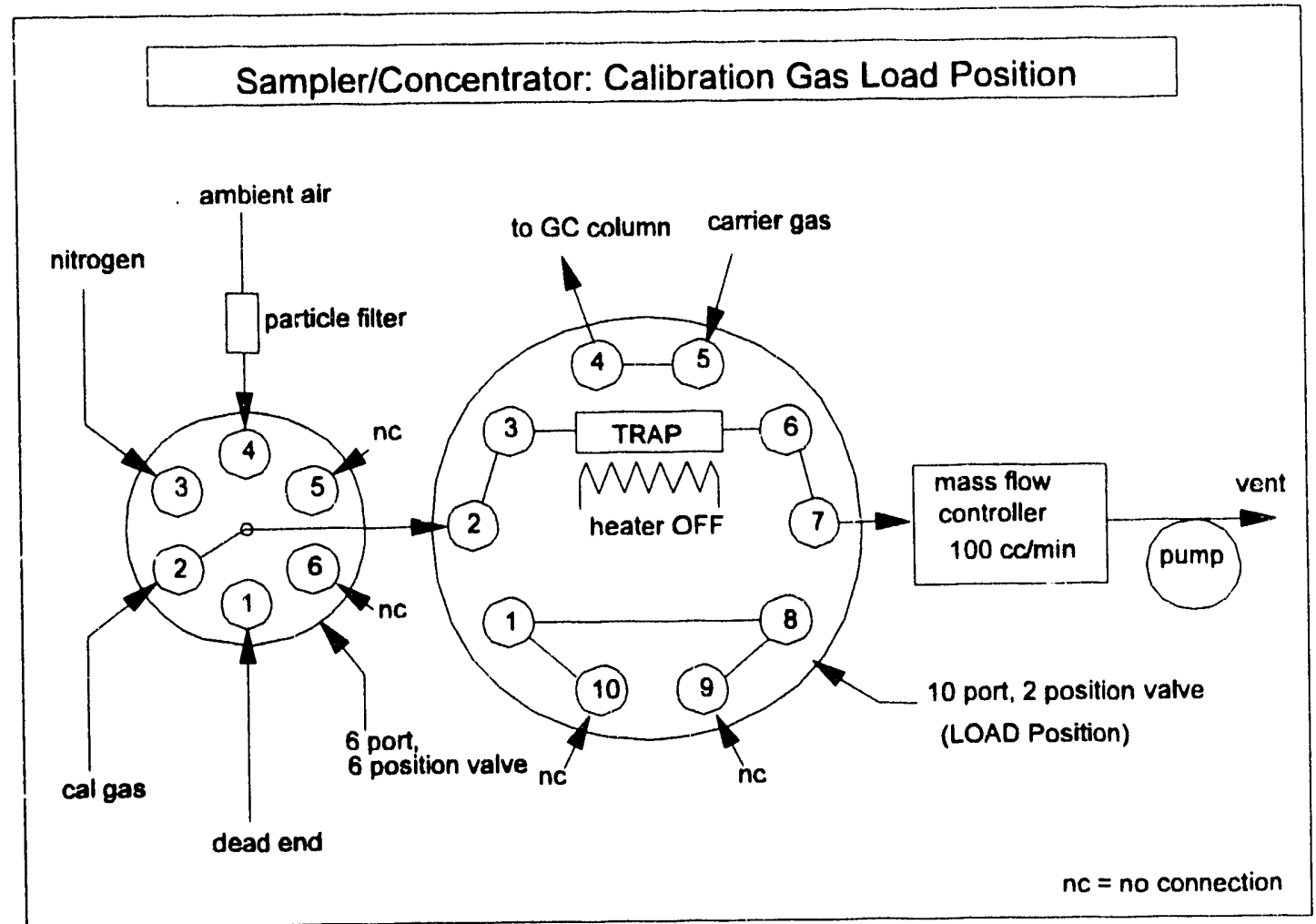

Figure 11. Valve position for calibration gas sample state. 


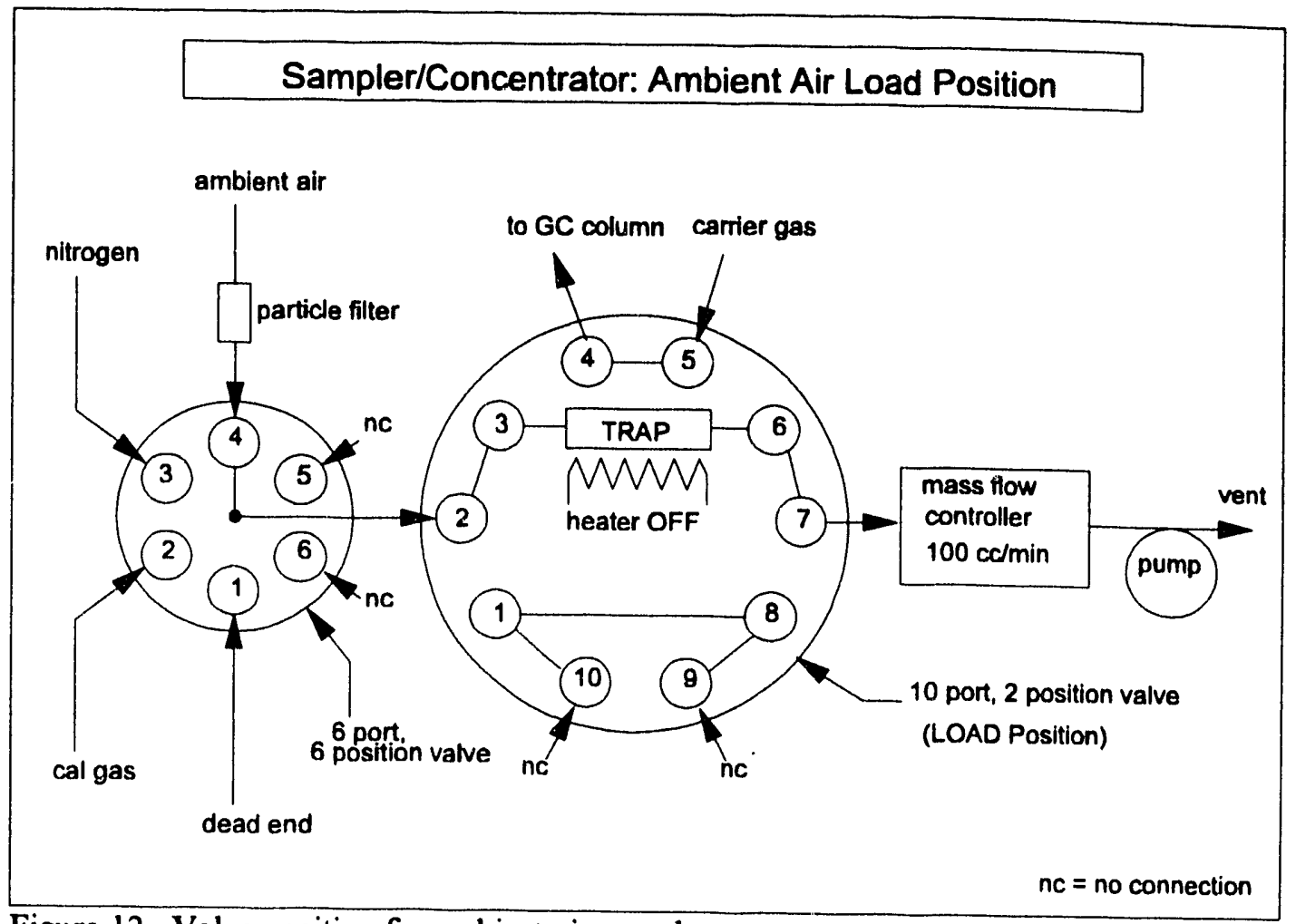

Figure 12. Valve position for ambient air sample state.

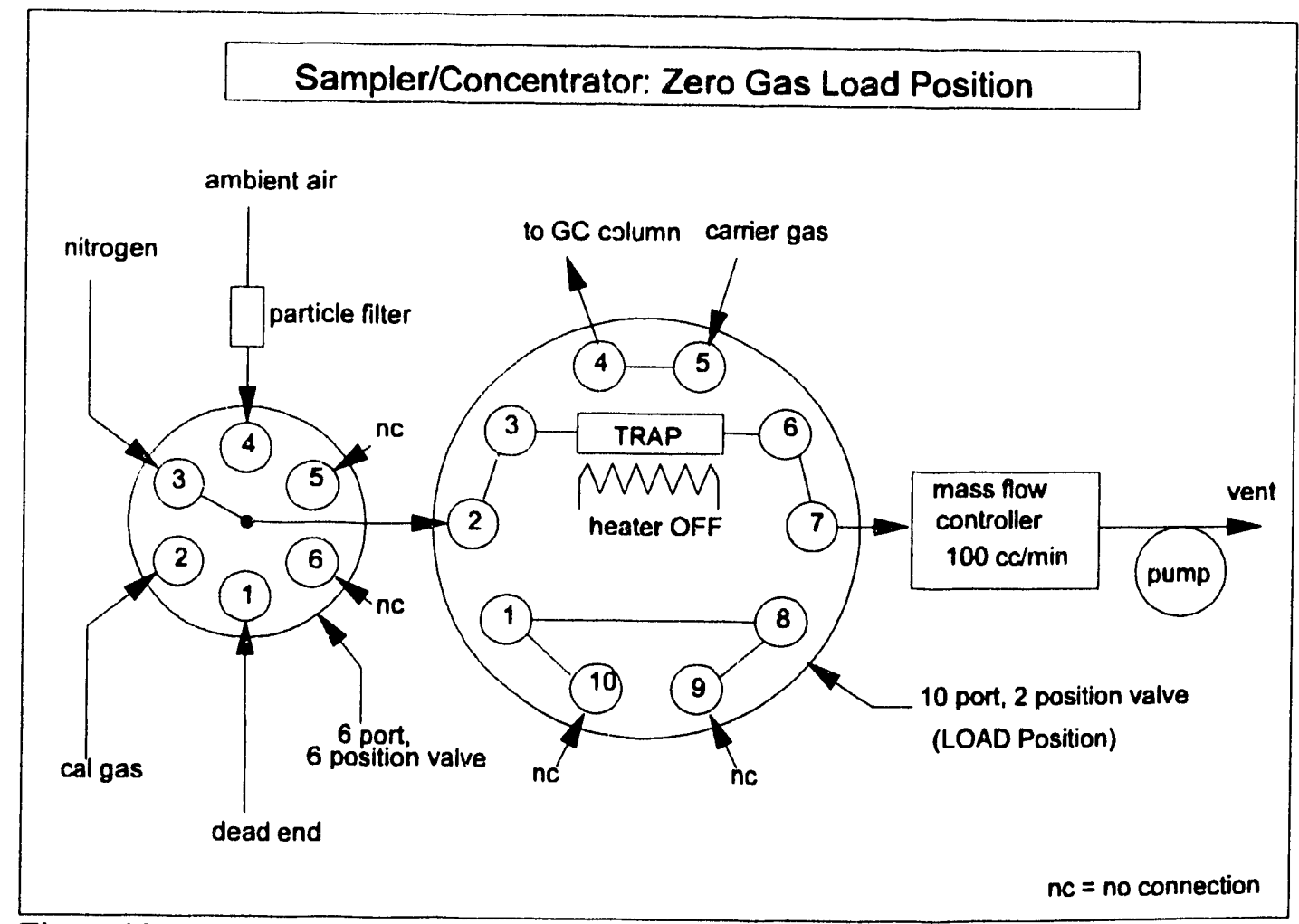

Figure 13. Valve position for zero air sample state. 


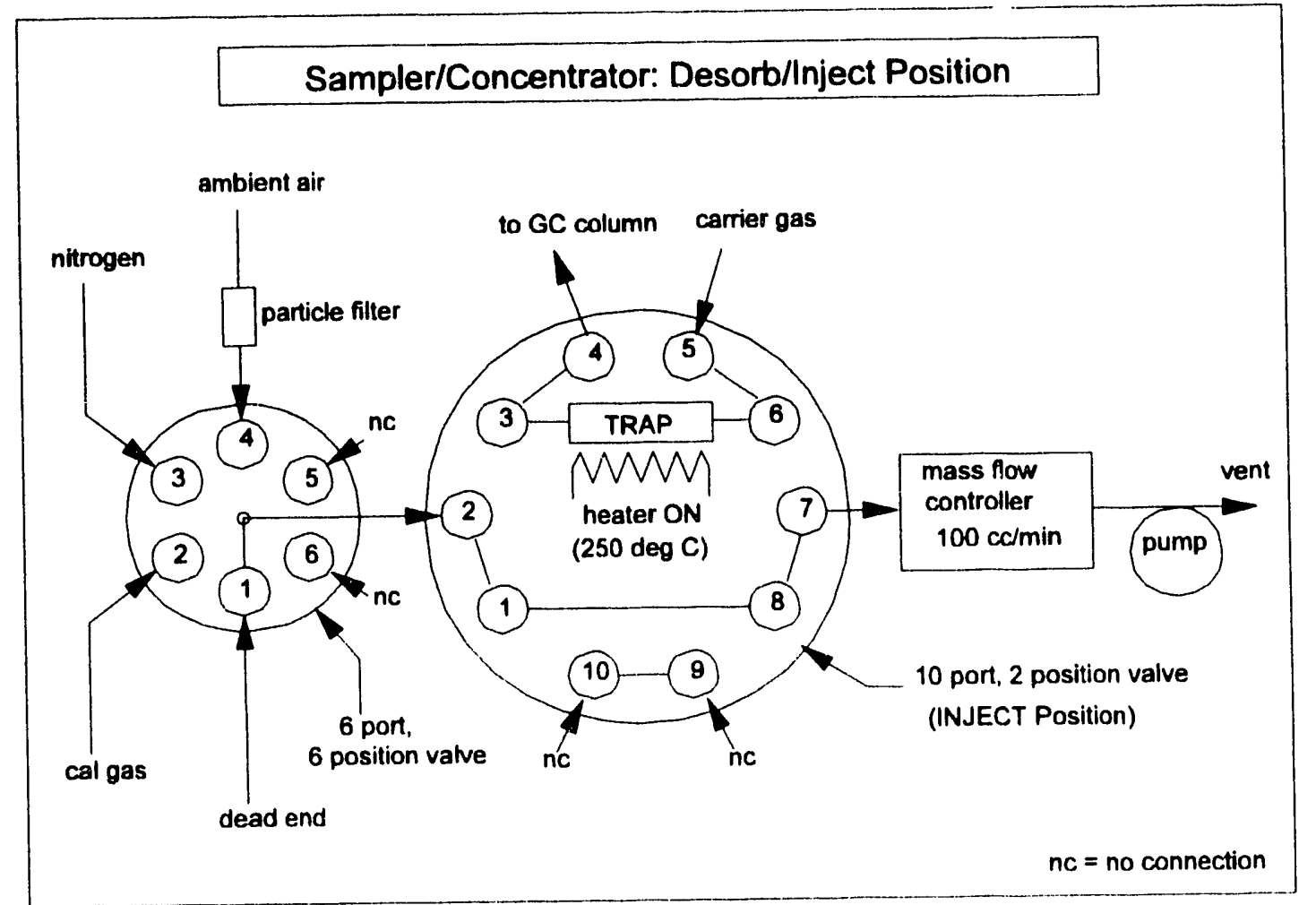

Figure 14. Valve position for inject/desorb onto column state.

For programming purposes the 6 states are mixed and matched into 1/2-hour entitities that perform particular functions. Timing diagrams for the 4 entities that comprise the run types (air sample, calibration, bakeout, and null) are shown in Figures 15 to 18. 


\section{Timing Diagram and Events Sequence for Air Sampling Runs}

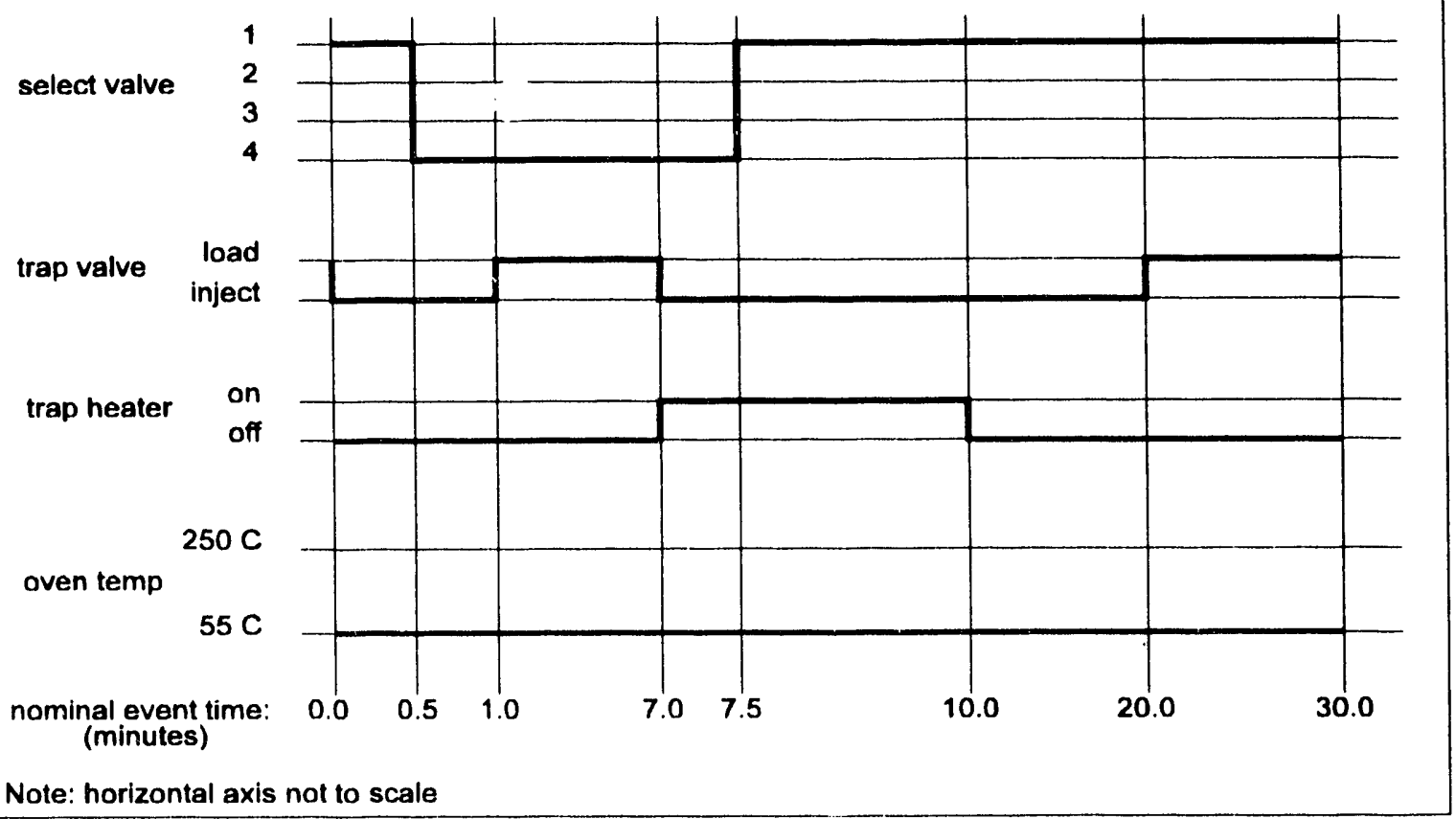

Figure 15. Timing diagram for air sample runs.

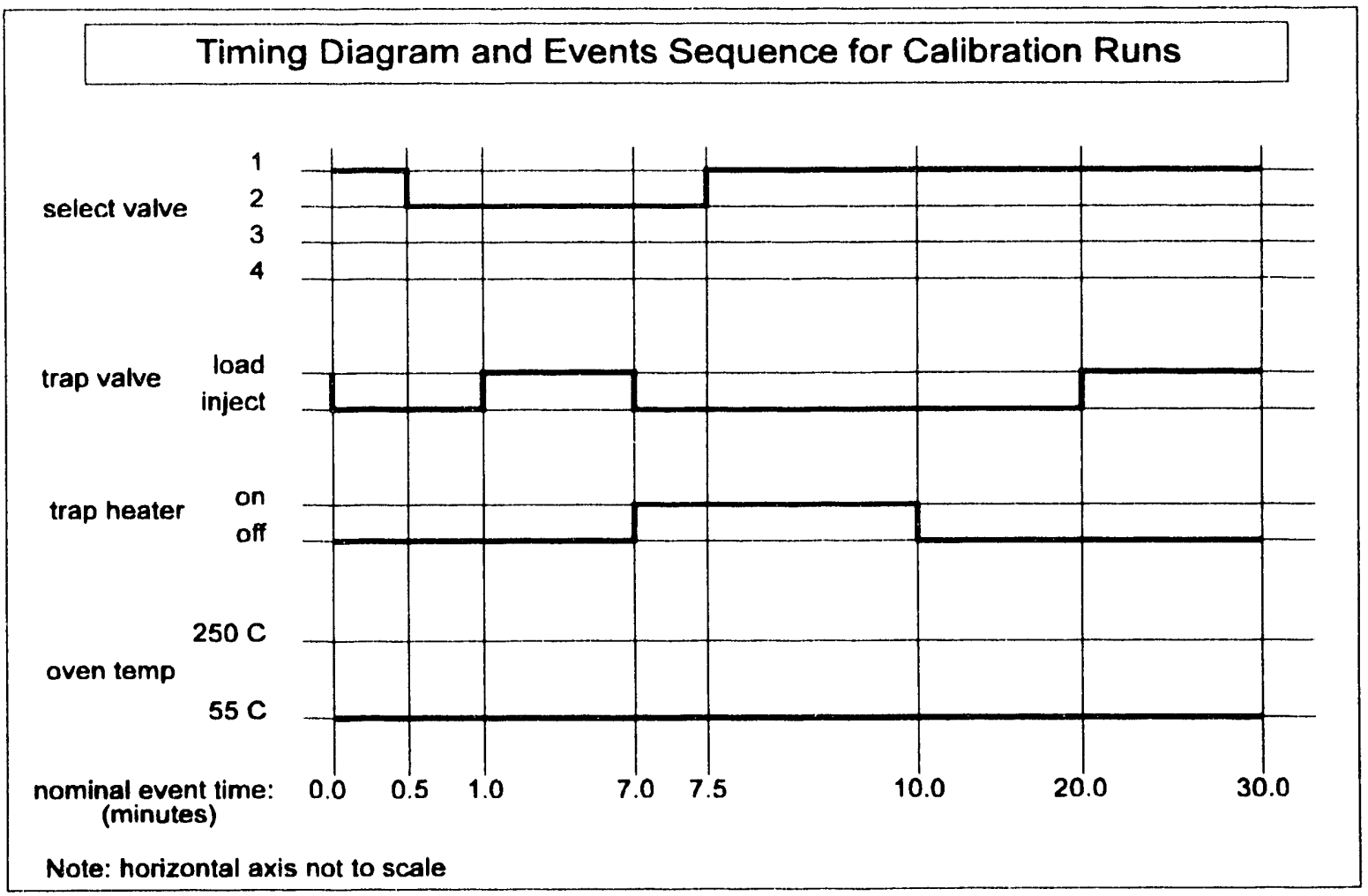

Figure 16. Timing diagram for calibration runs. 


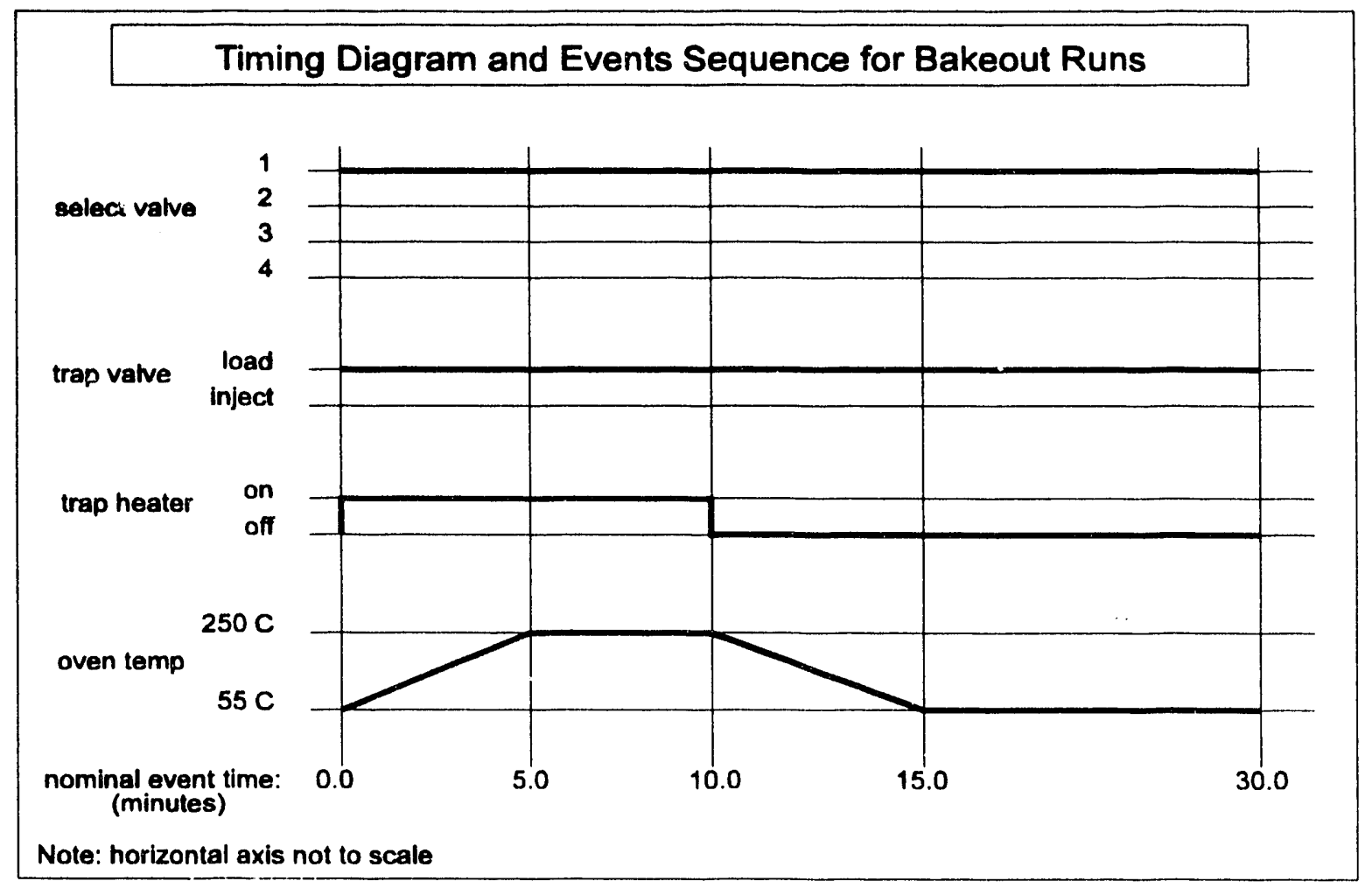

Figure 17. Timing diagram for bakeout runs.

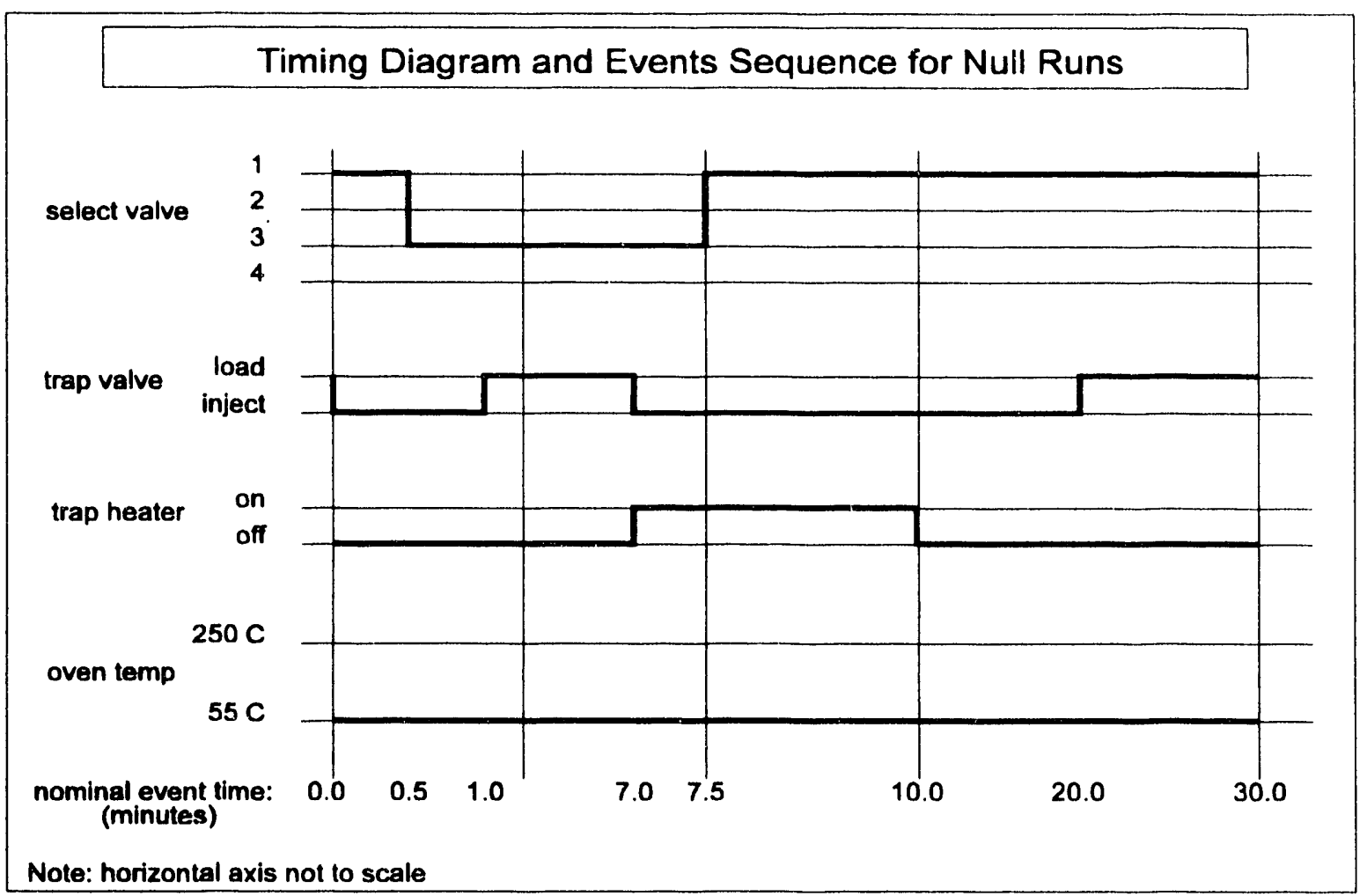

Figure 18. Timing diagram for null runs. 


\section{Power Requirements}

Supplying power from a portable gasoline fueled generator was studied, but found impractical because of the limited life of a tank of gas ( 5 hours max), noise, and concern that the exhaust gases could interfere with our measurements. For the field trials, power was obtained from the Incal power points at the GE and Tech Area III sites.

\section{Sampling Techniques}

Ambient air sampling techniques include:

- TO-14 Method (SUMMA ${ }^{\mathrm{TM}}$ Canisters)

- Tedlar bags

- Diffusion tubes (passive)

- Solvent desorption tubes

- Thermal desorption tubes

- Cold trap concentration

Ambient temperature trapping onto a charcoal sorbent with subsequent thermal desorption was chosen over all other methods because it requires no consumables, is suitable for a wide variety of VOCs, and is the most readily automatable. Difficulties with the other methods include: cost of cryogens like $\mathrm{CO}_{2}$ and $\mathrm{LN}_{2}$, and problems of icing in the system tubing.

\section{Gas Sampling Subsystem}

The gas sampler is designed to automatically pull a metered volume of gas through an activated carbon sorbent trap for concentrating VOCs prior to injection onto the GC column. The gas to be trapped is selected via an automatic 6 port stream select valve just upstream of the trap. The system is designed so that all sampled streams flow through the same pump and mass flow controller. See the design layout in Figure 19. This figure also serves as the pressure safety system diagram. 


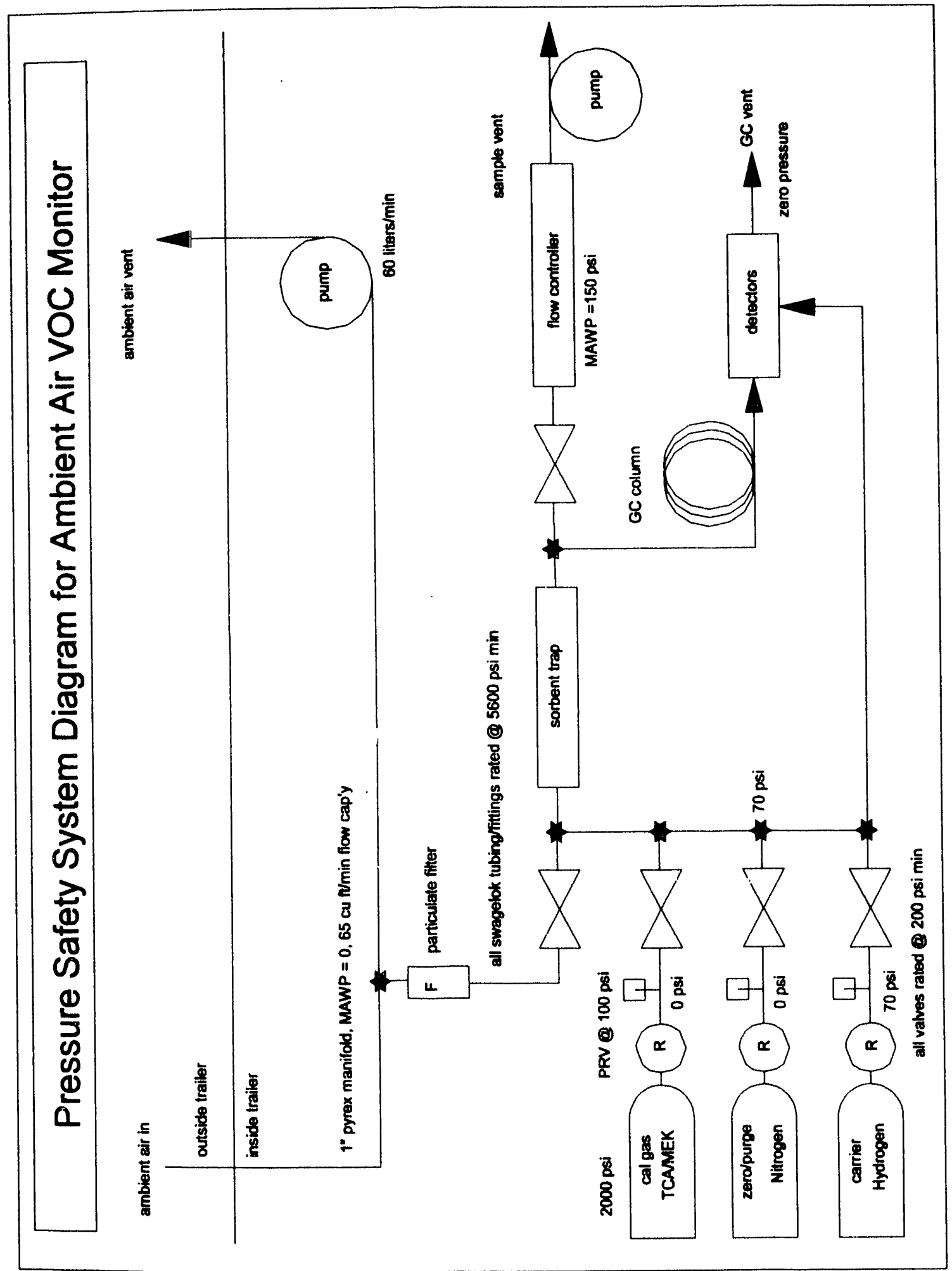

Figure 19. Tubing system diagram. 


\section{Design Rules}

The design rules for the sampler were:

- Maximize inertness of the materials used for tubing, fittings, valves, etc. (teflon, glass, stainless steel)

- Minimize dead volume everywhere, i.e., keep tubing as short as practical

- Minimize number of joints to minimize number of leakage paths

- Pull rather than push sample thru concentrator to minimize contamination by air mover, i.e., pump

- Use a sorbent with low break through voiume for $\mathrm{H}_{2} \mathrm{O}$ to eliminate need to dry sample

- No cryogenic concentration/focusing (cryogens are extremely expensive)

- Maximize desorb temperature ramp rate to ensure tipht slug is delivered to column

- desorb trap by backflushing to remove VOCs in reverse order that they were absorbed (to refocus the sample)

The gas is moved by a diaphragin pump and metered with a precision mass flow controller.

The pump was sized to provide up to $350 \mathrm{cc} / \mathrm{min}$ air flow against the pressure drop through the tubing, particle filter, valves, trap, and mass flow controller and is located dowrstream of the trap to prevent contamination of the sampling system.

A 2 micron particle filter at the air intake prevents dust, pollens, and other small particles from clogging the sampler. The mass flow rate thru the trap is preset on the mass flow conroller and sample size is simply the product of sample rate and sample time. Sample time is user programmable using the peak 2 control files. For our application the flow rate is preset at 100 cc std air per min. Sampling accuracy is $\pm 5 \mathrm{cc} / \mathrm{min}$. Standard conditions are $0^{\circ} \mathrm{C}$ and $760 \mathrm{~mm}$ $\mathrm{Hg}$.

The trap absorbs VOCs at ambient temperature. The trap is subsequently thermally desorbed at $250^{\circ} \mathrm{C}$ onto the $\mathrm{GC}$ column.

\section{Sample Volume}

Minimum sample volume is governed by the detection limit of the analytical method. For FID, the lower detection limit is 1 nanogram minimum for 1,1,1-TCA and MEK. Maximum sample size is governed by the breakthrough volume of the trap, column capacity, and detector saturation. For our system $600 \mathrm{cc}$ was a reasonable sample size for the concentrations of interest.

Sample volume is simply the product of time and flow rate as controlled by the mass flow controller. The total sample volume in local units, based on a perfect gas approximation is

where:

$$
\mathrm{V}=\mathbf{Q} \cdot \mathbf{t} \cdot \mathbf{P}_{\mathrm{c}} / \mathbf{P} \cdot \mathrm{T} / \mathrm{T}_{\mathrm{c}}
$$

$Q=$ measured air flow rate, $\mathrm{ml} / \mathrm{min}$

$\mathrm{t}=$ sample time, $\min$

$P_{c}=$ flowmeter calibration pressure, $\mathrm{mm} \mathrm{Hg}$

$\mathrm{P}=$ local air pressure, $\mathrm{mm} \mathrm{Hg}$

$\mathrm{T}_{\mathrm{c}}=$ flowmeter calibration temperature, $\operatorname{deg} \mathrm{K}$

$\mathbf{T}=$ local air temperature, $\operatorname{deg} \mathrm{K}$ 


\section{Sample Rate}

In general a long sampling time at low flow rate is preferable to a short sampling time at high flow rate. There are two reasons for this.

- Most health exposure standards are based on $8 \mathrm{hr}$ time weighted averages.

- Sorption efficiency is greater at lower flow rates.

Sample rates less than $10 \mathrm{ml} / \mathrm{min}$ are not recommended because of errors due to diffusion of the contaminants and because sample times become unnecessarily large.

Based on the air sampling literature (NIOSH \& EPA sampling guidelines) typical sample rates for sorbent tubes of our design are several tens of $\mathrm{cc} / \mathrm{min}$ to several hundred $\mathrm{cc} / \mathrm{min}$. Based on our own experiments, a $100 \mathrm{cc} / \mathrm{min}$ sample rate provided very repeatable results and allowed sample times to be kept reasonably short.

\section{Sorbent Selection}

The candidates for sorption of ambient air VOC vapors include but are not limited to activated charcoal, porous polymers, molecular sieves, and silica gel. The sorbents evaluated were:

- Tenax TA

- Carbotrap B

- Carbotrap C

- Carbosieve S-III

- Activated Coconut Charcoal 20/40 mesh

- Carboxen-564

Molecular sieves and Silica gel were not considered practical because of their affinity for moisture. The carbotrap B was selected since it is a good general purpose sorbent for a variety of VOCs. The Carbotrap sorbent has the advantage of very low breakthrough volume for water, hence it can be used in high humidity environments without the need for drying the samples.

\section{The Detector}

The detector chosen was a Flame-Ionization Detector (FID) because it is responsive to almost all organics, and has more than enough sensitivity to provide detection at the concentrations of interest. The FID also has the advantages of a large dynamic range $\left(10^{7}\right)$ and low sensitivity to water and most inorganics.

\section{Gas Supply Subsystem}

Four gases are used by the system:

- UHP Hydrogen (carrier \& FID fuel)

- UHP Nitrogen (zero gas and purge gas)

- Calibration gas $=10$ ppmv MEK, 10 ppmv 1,1,1 TCA, balance $\mathrm{N}_{2}$

- Air (for FID) supplied by a built-in compressor

Each gas supply line is equipped with an excess flow valve that will shut off flow in case of a large leak or catastrophic failure of the system, and a pressure relief valve to vent any pressure build ups in the system. The assembly diagrams for the first 3 gas lines are provided in Figures 20-22. 


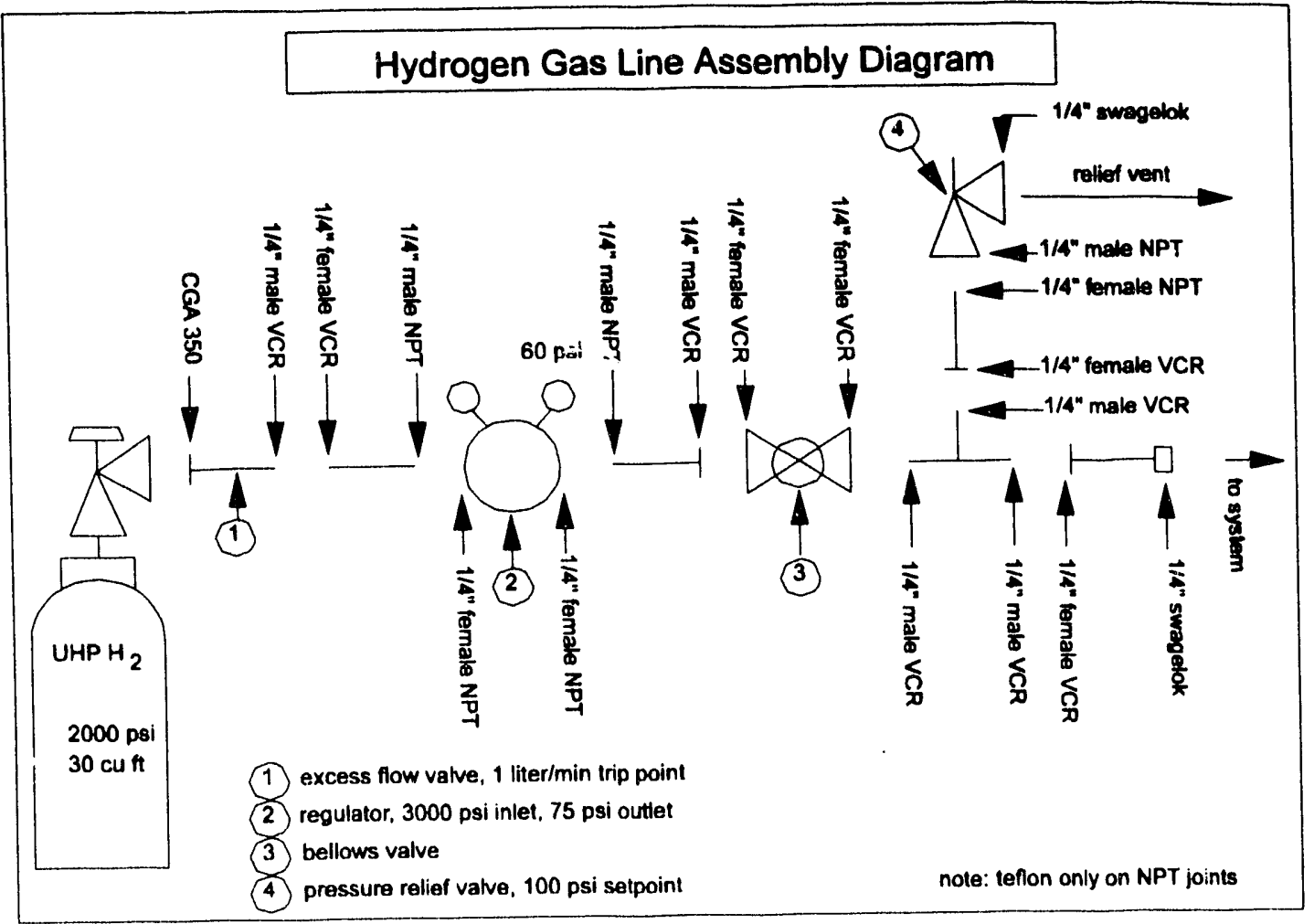

Figure 20. Hydrogen gas line assembly.

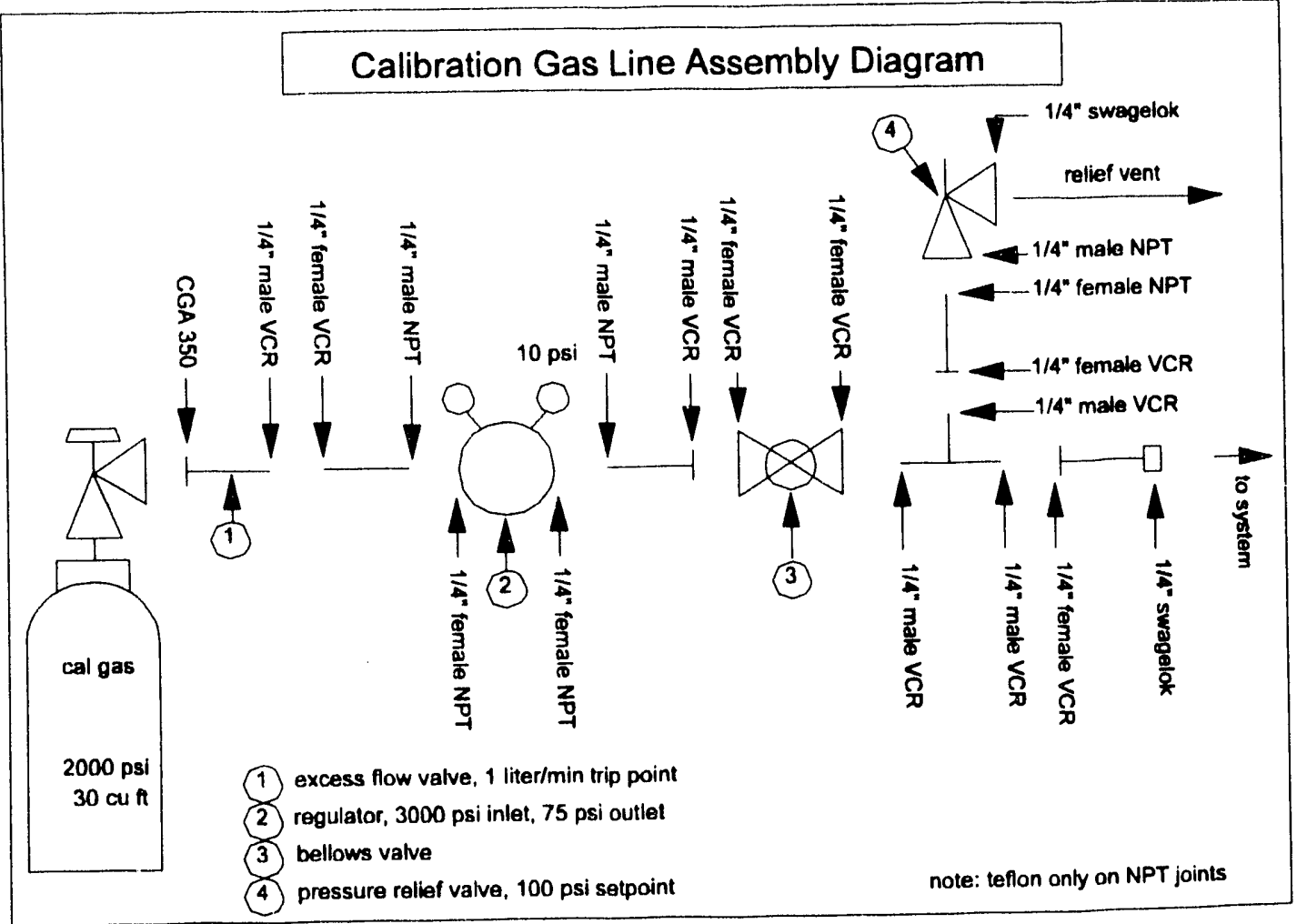

Figure 21. Calibration gas line assembly. 


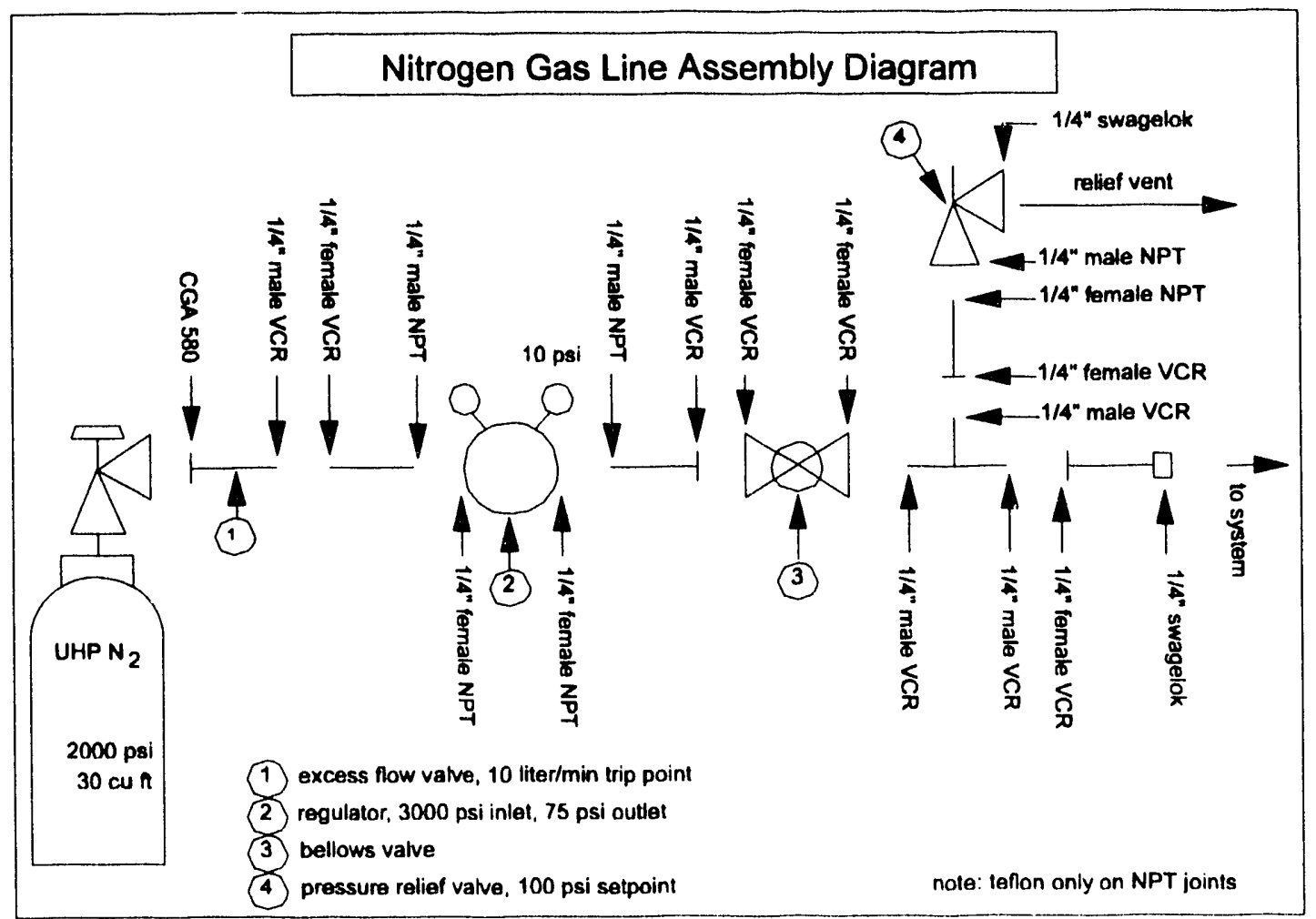

Figure 22. Nitrogen gas line assembly.

Tubing Cleaning and Checkout Procedure

1. acetone rinse

2. blow dry with air canister

3. repeat

4. After assembly into the system, the tubing was wrapped with heat tape, heated to $250^{\circ} \mathrm{C}$ and flushed with dry Nitrogen to further remove trace contaminants.

5. All gas lines were leak checked at 100 psi with Snoop liquid leak detector.

6. The gas cylinder regulator output pressures were then set to:

$\begin{array}{ll}\text { hydrogen: } & 60 \mathrm{psi} \\ \text { nitrogen: } & 10 \mathrm{psi} \\ \text { cal gas: } & 10 \mathrm{psi}\end{array}$

Gas flow rates \& Estimate of gas usage gas

$$
\begin{aligned}
& \text { flow rate duty cycle use/day use/month source source life } \\
& \text { (cc/min) (liters) (liters) cap'y (cu (days) }
\end{aligned}
$$

ft)

hydrogen:

carrier

FID fuel

total

nitrogen

cal gas
100.0

1.00

0.10

0.02

100.0

35.6
14.4
2.9

1067.0
2.9 
All compressed gases are supplied in $\# 3$ cylinders ( $2000 \mathrm{psi}, 29 \mathrm{cu} \mathrm{ft}$ ). FID air is supplied by an internal compressor at $250 \mathrm{cc} / \mathrm{min}$ and is continuously generated, therefore no compressed air is required.

\section{Maintenance}

The maintenance required is periodic replacement of the hydrogen, nitrogen, and calibration gas, replacement of the nitrogen and hydrogen gas filters, cleaning of the ambient air particle filter, and perhaps cleaning of the FID electrode.

- Gas replacement: The gases should be replaced when the tank pressure gage reads 200 psi or less. Life expectancy of the gas cylinders is shown in the table above.

- $\mathrm{H}_{2} \& \mathrm{~N}_{2}$ gas filters: Supelco OMI-1 indiciating purifiers are used. When the filter material turns completely brown, the filter must be replaced. Life expectancy with our system is on the order of several months of continuous usage. Used filters may be discarded in the trash.

- $\quad$ Particle filter: Nupro 2 micron stainless steel frit. Can be cleaned without removing the filter body.

- FID detector cleaning: If a reduction in FID response is noted over a period of time, it may be time to clean deposits from the FID electrode. See the SRI GC manual for guidance on disassembly and cleaning.

\section{GC Interface Card Pinout}

Pin

CH1 FID signal input

$\mathrm{CH} 2$ not used

A Stream Select Valve Step

B Stream Select Valve Home

C not used

D not used

E not used

F Trap Heater \#1 ON

G Trap Valve to Inject Position

H Trap Valve to Load Position

White GC Oven setpoint

Dgnd Ground for relays \& oven temp setpoint

\section{Type of Function}

AVD

A/D

Relay closure

"

II

II

11

11

"

Analog

\section{System Figures}

Figure 23 shows a photograph of the overall system inside the trailer. Figure 24 shows the weather station. 


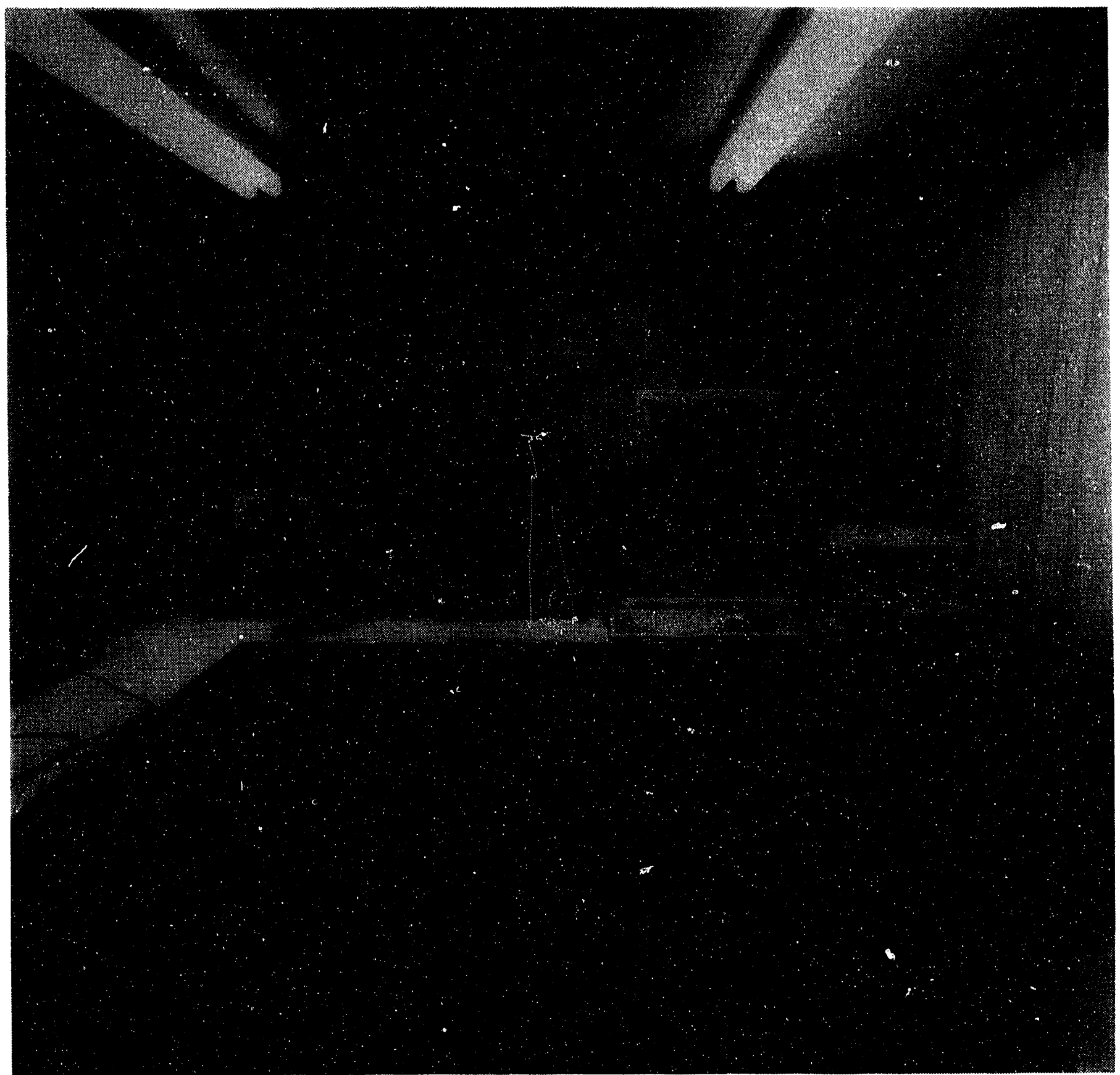

Figure 23. System components inside the trailer. 


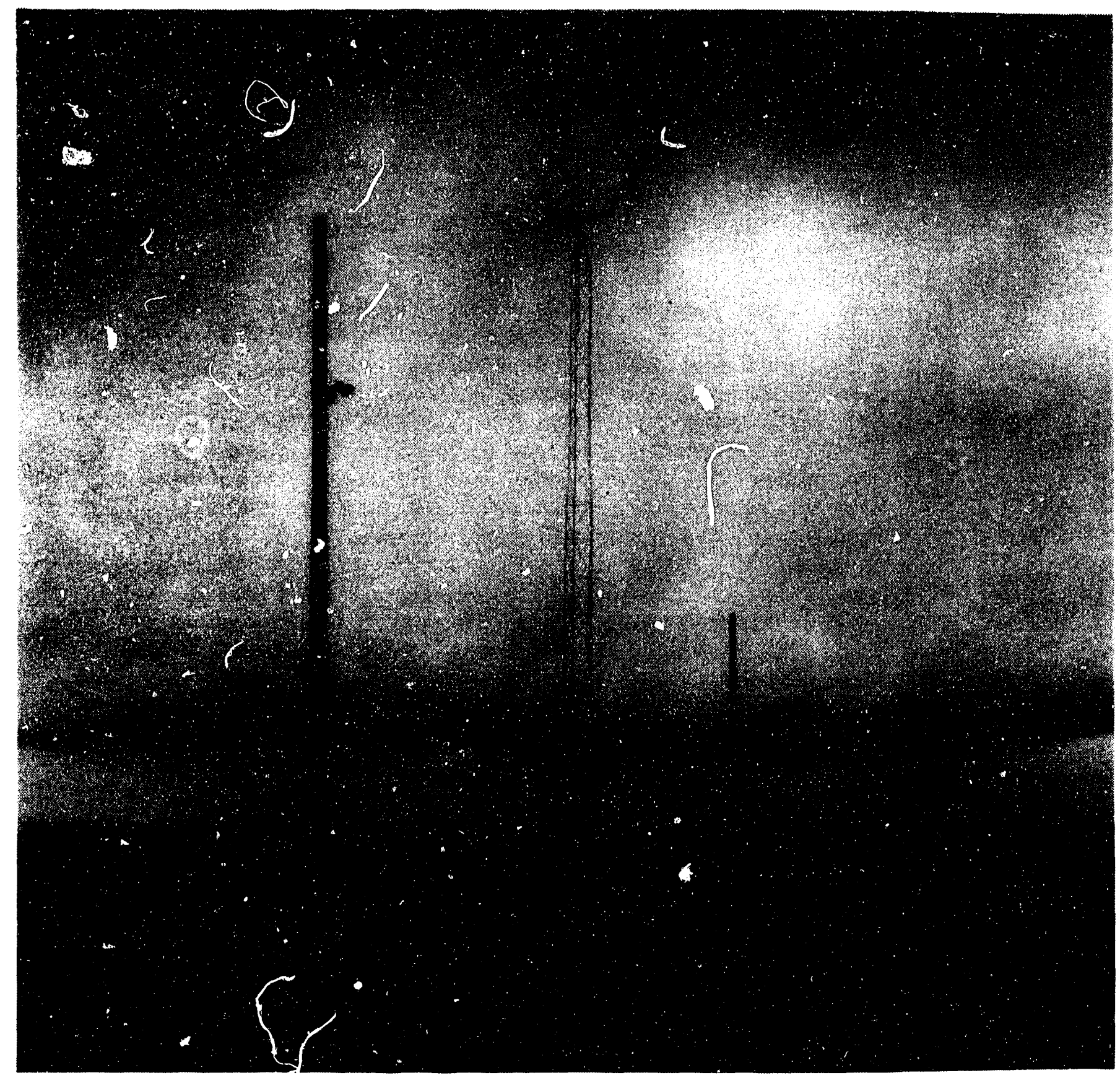

Figure 24. Weather station subsystem. 


\section{E. Software Description}

The software provided with the gas chromatograph, PeakSimple II Version 3.44, is highly automated, but there are a number of initialization steps that need operator keystroke operations. The parts of the PeakSimple II program that needed these operator keystrokes were a) starting the data acquisition process and b) saving the data after acquisition to a unique data file name. We used SuperKey Version 1.1. from Borland International to send these required keystrokes to operate the PeakSimple II program. A C ++ program was written to control the time a run is started, type of run, and to generate unique data file names. The following paragraphs describe the SuperKey macro files and the $\mathrm{C}++$ program RANDRUN. C that were used to automate the gas chromatograph.

\section{RANDRUN.C}

Randrun, version 1.0, was written in $\mathrm{C}++$ and controls the entire automated gas chromatograph system. RANDRUN runs continuously after it is started, and can only be stopped by entering a $\langle\mathrm{Ctrl}-\mathrm{Break}>$ while the program is waiting for the next run time to occur. The Randrun program performs the following functions:

1. One of nine text files containing run times and batch files (SuperKey macro batch files) is randomly selected. A listing of the nine text files (CLKEILEO. TXT through CLKEILE 8. TXT) can be found in Software Listing section of this report. The contents of the chosen text file is copied into an array. A different text file is chosen each new day at midnight.

2. A data sub directory is created under $D: \backslash P E A K 2 \backslash D A T A \backslash$ (or under $C: \backslash P E A K 2 \backslash D A T A \backslash$ if drive $D:$ is not working) in the format MMMDD_YY (Month, Day, Year). A new directory is made at midnight for the new day.

3. Data from a weather station is acquired by executing WEATHER. BAT. (See section Weather Station Files). Data file C: \WEATHER \CITY_ABQ. DAT is then deleted.

4. Compares the current time to each time element in the time and batch file array. If a match is found, the corresponding batch file is executed. The data taken by the gas chromatograph during the run (file C: $\backslash$ WEATHER $\backslash F I D \_D A T A . A S C$ ) is then copied to a data file name in the format MMDDH Hmm (Month, Day, Hour, minute) with the file extension . * where * is the first character in the batch file name. The data is stored under the data sub directory made for the current date

5. Weather data is retrieved from the weather station and is stored to the same file name and sub directory listed above, except that the file extension is always . W for weather data.

6. The program continues to compare times until a match is found in the array. While the program is comparing times and waiting for the next run time, the time and date are displayed to the screen.

A flowchart of RANDRUN. C and a listing of the code can be found in Software Listing section of this report.

\section{SuperKey Macros and Auto-Run Batch Files}

SuperKey works by executing a sequence of keystrokes, or macro, as defined in an ASCII text file. All SuperKey macros files have the file extension . MAC. In the macro file, one key is assigned as the key to be pressed to execute the macro. SuperKey macros can also be made to start automatically when loaded at the DOS prompt by including the $<$ AUTO $>$ statement after 
the key assignment statements at the beginning of the macro file. The SuperKey program must be loaded into memory before a SuperKey macro can be executed.

All of the macros written for the project are assigned to the $\langle F 12\rangle$ key, and are auto-starting. DOS batch files are used to load the auto-starting macros and to execute them automatically after the PeakSimple program is started. Refer to the Software Listing section for a listing of all macro files and batch files. When one of the batch files is executed, the following sequence of events occur (batch commands are in parentheses):

1. SuperKey is loaded into memory. (key)

2. Any SuperKey macros in memory at this time are cleared from memory. $(/ \mathrm{mc})$

3. A macro to operate the PeakSimple program is loaded and SuperKey is activated. (air_6/ml/ou-)

4. The PeakSimple II program is loaded and the macro executes automatically. (peak2)

5. After the macro has been executed, the Superk.ey program is suspended. (key lout)

After the PeakSimple II program has been started by the batch file, the macro causes the following sequence of events occurs within the PeakSimple II menu shell:

1. A PeakSimple II control file is loaded. (AIR_6.CON, CAL_6.CON, or BAKEOUT . CON)

2. PeakSimple II is set up so that data will be stored in an ASCII format.

3. The chromatograph run is started.

4. SuperKey waits the time it takes the for chromatograph to finish running (the time is listed in the macro file), and then causes the PeakSimple program to quit.

A difficulty of using SuperKey to operate PeakSimple II is that some changes made to PeakSimple control files, such as total run time and control file name, must also be reflected in the associated SuperKey macro file and batch file. Otherwise, the SuperKey program worked very well for this application.

\section{Weather Station Files}

All of the program files used to acquire weather data from the Campbell CR10 Data Logger can be found under C: \WEATHER. The weather data programs were provided by Department 6612 personnel. A batch file stored under directory $C: \backslash P E A K 2$ was used with Randrun so that the ASCII weather data collected (file CITY_ABQ. DAT) would be automatically stored under the $C: \backslash$ WEATHER directory. Below is a listing of the WEATHER. BAT file:

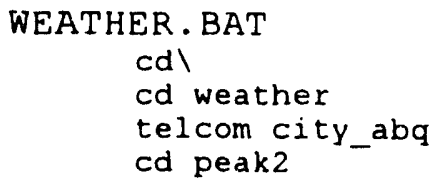

Data retieved by executing TELCOM CITY_ABQ is appended to the file CITY ABQ. DAT.

If only new data is wanted, the weather data file must be deleted before TELCOM CITY_ABQ is executed.

\section{AUTOEXEC.BAT}

The AUTOEXEC. BAT file for the computer was modified so that the Randrun program is automatically started when the computer is rebooted. That is, the last line in the AUTOEXEC. BAT file is RANDRUN. This was done so that the program would restart automatically after a power outage. 
Software Listings

SuperKey macros and batch files

AIR 6.MAC

<BEGDEF><F12><AUTO><ENTER>01<ENTER>

aix 6. CON<ENTER>

〈ENTER>

$C s<\mathrm{TAB}\rangle\langle\mathrm{TAB}\rangle\langle\mathrm{TAB}\rangle\langle\mathrm{TAB}\rangle\langle\mathrm{DN}\rangle\langle\mathrm{ENTER}\rangle$

$<$ TAB $><T A B><E N T E R>$

Cr<CMD $>$ FR00:25:30.00<CMD>q Q ENTER

<BNDDEF>

\section{CAL6.MAC}

<BEGDEF><F12><AUTO><ENTER>01<ENTER>

cal_6. CON<ENTER>

<ENTER>

CS $\langle\mathrm{TAB}\rangle\langle\mathrm{TAB}\rangle\langle\mathrm{TAB}\rangle\langle\mathrm{TAB}\rangle\langle\mathrm{DN}\rangle\langle\mathrm{ENTER}\rangle$

$\langle$ TAB $\rangle\langle$ TAB $><$ ENTER $>$

Cr $<C M D>F R 00: 25: 30.00<C M D>q<E N T E R>$

〈ENDDEF>

\section{BAKEOUT.MAC}

<BEGDEF $>\langle$ F $12>\langle A U T O><E N T E R>01<E N T E R>$

bakeout. CON<ENTER>

<ENTER>

Cs $\langle T A B\rangle\langle T A B\rangle\langle T A B\rangle\langle T A B\rangle\langle D N\rangle\langle E N T E R\rangle$

$\langle$ TAB $\rangle\langle$ TAB $><$ ENTER $>$

Cr<CMD>ER00:25:30.00<CMD>q<ENTER> <ENDDEF>

\author{
AIR 6.BAT \\ key $/ \mathrm{mc}$ air_6/ml /ou- \\ peak2 \\ key /out
}

\section{CAL6.BAT}

key /mc cal 6/ml /ou-

peak2

key /out

\section{BAKEOUT.BAT}

key /mc bakeout/ml /oupeak2

key lout 


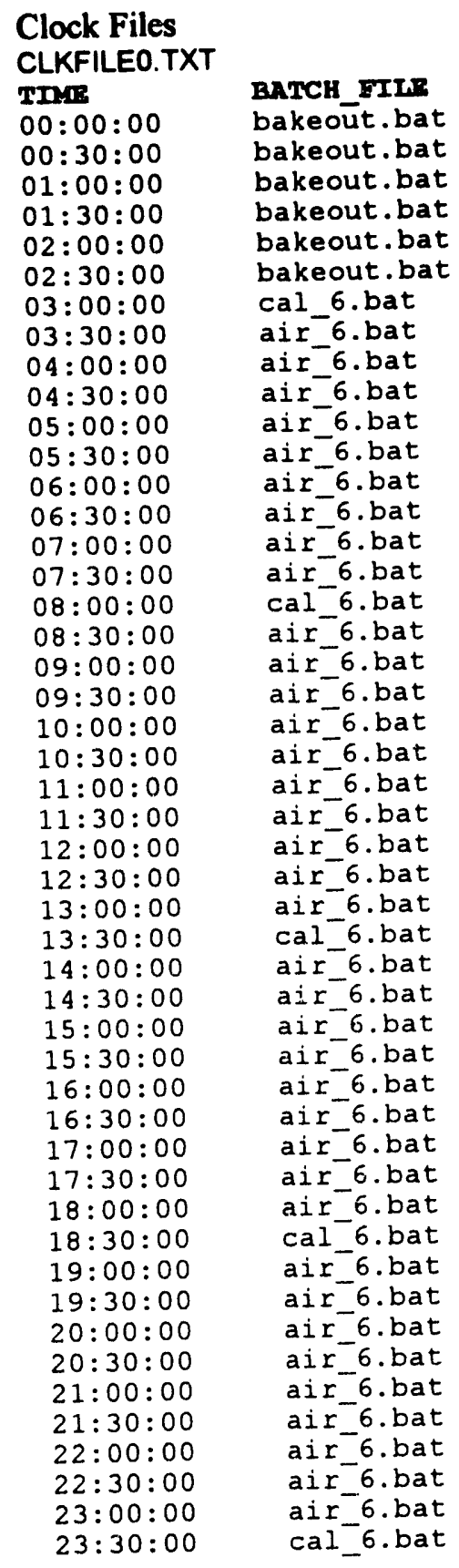

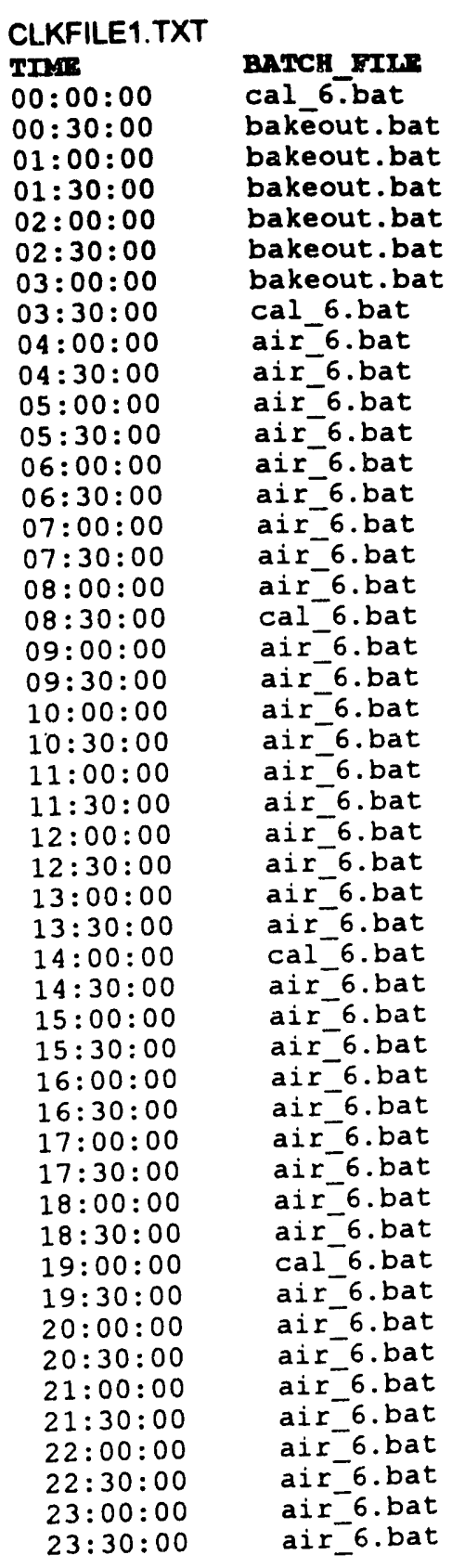




CLKFILE2.TXT
TIIE
$00: 00: 00$
$00: 30: 00$
$01: 00: 00$
$01: 30: 00$
$02: 00: 00$
$02: 30: 00$
$03: 00: 00$
$03: 30: 00$
$04: 00: 00$
$04: 30: 00$
$05: 00: 00$
$05: 30: 00$
$06: 00: 00$
$06: 30: 00$
$07: 00: 00$
$07: 30: 00$
$08: 00: 00$
$08: 30: 00$
$09: 00: 00$
$09: 30: 00$
$10: 00: 00$
$10: 30: 00$
$11: 00: 00$
$11: 30: 00$
$12: 00: 00$
$12: 30: 00$
$13: 00: 00$
$13: 30: 00$
$14: 00: 00$
$14: 30: 00$
$15: 00: 00$
$15: 30: 00$
$16: 00: 00$
$16: 30: 00$
$17: 00: 00$
$17: 30: 00$
$18: 00: 00$
$18: 30: 00$
$19: 00: 00$
$19: 30: 00$
$20: 00: 00$
$20: 30: 00$
$21: 00: 00$
$21: 30: 00$
$22: 00: 00$
$22: 30: 00$
$23: 00: 00$
$23: 30: 00$

\section{CKFILE3.TXT}

BATCH FILE

air 6.bat

cal-6.bat

bakēout.bat

bakeout . bat

bakeout . bat

bakeout . bat

bakeout.bat

bakeout.bat

cal_6.bat

air 6. bat

air-6.bat

air 6.bat

air 6.bat

air-6.bat

air_6.bat

air-6.bat

air 6.bat

air_6.bat

cal 6.bat

air_6.bat

air 6.bat

air_6.bat

air 6.bat

air_6.bat

air 6.bat

air 6.bat

air 6.bat

air 6.bat

air-6.bat

cal 6.bat

air 6.bat

air 6.bat

air-6.bat

air 6.bat

air_6.bat

air 6.bat

air 6.bat

air 6.bat

air-6.bat

cal-6.bat

air 6.bat

air 6.bat

air 6.bat

air 6 .bat

air_6.bat

air-6.bat

air 6.bat

air-6.bat
$00: 00: 00$

$00: 30: 00$

$01: 00: 00$

$01: 30: 00$

$02: 00: 00$

$02: 30: 00$

03:00:00

$03: 30: 00$

$04: 00: 00$

$04: 30: 00$

$05: 00: 00$

$05: 30: 00$

06:00:00

$06: 30: 00$

07:00:00

$07: 30: 00$

$08: 00: 00$

$08: 30: 00$

09:00:00

09:30:00

10:00:00

$10: 30: 00$

$11: 00: 00$

$11: 30: 00$

$12: 00: 00$

$12: 30: 00$

$13: 00: 00$

$13: 30: 00$

14:00:00

$14: 30: 00$

$15: 00: 00$

$15: 30: 00$

$16: 00: 00$

$16: 30: 00$

$17: 00: 00$

$17: 30: 00$

$18: 00: 00$

$18: 30: 00$

$19: 00: 00$

19:30:00

20:00:00

$20: 30: 00$

21:00:00

$21: 30: 00$

22:00:00

$22: 30: 00$

23:00:00

$23: 30: 00$
BATCH FIIS

air_6.bat

air 6.bat

cal-6.bat

bakeout.bat

bakeout.bat

bakeout.bat

bakeout.bat

bakeout. bat

bakeout.bat

cal_6.bat

air 6.bat

air-6.bat

air 6.bat

air 6.bat

air 6.bat

air-6.bat

air 6.bat

air_6.bat

air 6.bat

cal-6.bat

air-6.bat

air 6.bat

air 6.bat

air 6.bat

air_6.bat

air 6.bat

air_6.bat

air 6.bat

air 6.bat

air 6.bat

cal-6.bat

air 6.bat

air 6 .bat

air-6.bat

air 6.bat

air_6.bat

air 6 .bat

air-6.bat

air 6.bat

air-6.bat

cal 6.bat

air-6.bat

air 6.bat

air_6.bat

air 6.bat

air-6.bat

air-6.bat

air_6.bat 
CLKFILE4.TXT

TDE

$00: 00: 00$

$00: 30: 00$

$01: 00: 00$

$01: 30: 00$

$02: 00: 00$

$02: 30: 00$

$03: 00: 00$

$03: 30: 00$

04:00:00

$04: 30: 00$

$05: 00: 00$

$05: 30: 00$

06:00:00

06:30:00

07:00:00

$07: 30: 00$

08:00:00

$08: 30: 00$

09:00:00

$09: 30: 00$

$10: 00: 00$

$10: 30: 00$

$11: 00: 00$

$11: 30: 00$

$12: 00: 00$

$12: 30: 00$

$13: 00: 00$

$13: 30: 00$

$14: 00: 00$

$14: 30: 00$

$15: 00: 00$

$15: 30: 00$

$16: 00: 00$

$16: 30: 00$

$17: 00: 00$

$17: 30: 00$

$18: 00: 00$

$18: 30: 00$

$19: 00: 00$

$19: 30: 00$

$20: 00: 00$

$20: 30: 00$

21:00:00

$21: 30: 00$

$22: 00: 00$

$22: 30: 00$

$23: 00: 00$

$23: 30: 00$
BATCH FIIE

air 6.bat

air-6.bat

air 6.bat

cal_6.bat

bakeout.bat

bakeout.bat

bakeout . bat

bakeout.bat

bakeout.bat

bakeout.bat

cal_6.bat

air_6.bat

air_6.bat

air_6.bat

air_6.bat

air 6.bat

air_6.bat

air 6.bat

air_6.bat

air 6.bat

cal-6.bat

air 6.bat

air_6.bat

air-6.bat

air-6.bat

air_6.bat

air 6 .bat

air-6.bat

air 6.bat

air_6.bat

air 6.bat

cal-6.bat

air 6.bat

air 6 .bat

ais 6 .bat

air_6.bat

air 6.bat

air-6.bat

air 6 .bat

air 6.bat

air-6.bat

cal-6.bat

air 6.bat

air 6.bat

air_6.bat

air 6.bat

air 6.bat

air_6.bat

\section{CLKFILE5.TXT}

\section{TIN:}

00:00:00

$00: 30: 00$

$01: 00: 00$

$01: 30: 00$

$02: 00: 00$

$02: 30: 00$

$03: 00: 00$

$03: 30: 00$

$04: 00: 00$

$04: 30: 00$

$05: 00: 00$

$05: 30: 00$

$06: 00: 00$

$06: 30: 00$

$07: 00: 00$

$07: 30: 00$

$08: 00: 00$

$08: 30: 00$

$09: 00: 00$

$09: 30: 00$

$10: 00: 00$

$10: 30: 00$

$11: 00: 00$

$11: 30: 00$

$12: 00: 00$

$12: 30: 00$

$13: 00: 00$

$13: 30: 00$

$14: 00: 00$

$14: 30: 00$

$15: 00: 00$

$15: 30: 00$

$16: 00: 00$

$16: 30: 00$

$17: 00: 00$

$17: 30: 00$

$18: 00: 00$

$18: 30: 00$

19:00:00

$19: 30: 00$

20:00:00

$20: 30: 00$

21:00:00

$21: 30: 00$

22:00:00

$22: 30: 00$

23:00:00

$23: 30: 00$
BATCH_EILE

air 6.bat

air 6 .bat

air-6.bat

air 6 .bat

cal-6.bat

bakeout .bat

bakeout . bat

bakeout . bat

bakeout . bat

bakeout . bat

bakeout . bat

cal 6.bat

air-6.bat

air 6 .bat

air_6.bat

air 6 .bat

air 6 .bat

air 6 .bat

air 6 .bat

air 6 .bat

air 6 .bat

cal-6.bat

air 6 .bat

air-6.bat

air 6.bat

air 6 .bat

air 6.bat

air_6.bat

air 6.bat

air_6.bat

air 6 .bat

air 6.bat

cal-6.bat

air 6.bat

air 6 .bat

air 6.bat

air-6.bat

air 6.bat

air-6.bat

air 6.bat

air-6.bat

air 6.bat

cal-6.bat

air 6 .bat

air_6.bat

air 6.bat

air_6.bat

air_6.bat 


\section{CLKFILE6.TXT}

\section{III.1}

00:00:00

$00: 30: 00$

01:00:00

$01: 30: 00$

02:00:00

$02: 30: 00$

03:00:00

$03: 30: 00$

04:00:00

$04: 30: 00$

$05: 00: 00$

05: $30: 00$

$06: 00: 00$

06:30:00

Q7:00:00

$07: 30: 00$

08:00:00

$08: 30: 00$

09:00:00

$09: 30: 00$

$10: 00: 00$

$10: 30: 00$

$11: 00: 00$

$11: 30: 00$

$12: 00: 00$

$12: 30: 00$

$13: 00: 00$

$13: 30: 00$

$14: 00: 00$

$14: 30: 00$

$15: 00: 00$

$15: 30: 00$

$16: 00: 00$

$16: 30: 00$

$17: 00: 00$

$17: 30: 00$

$18: 00: 00$

$18: 30: 00$

$19: 00: 00$

$19: 30: 00$

20:00:00

$20: 30: 00$

$21: 00: 00$

$21: 30: 00$

$22: 00: 00$

$22: 30: 00$

23:00:00

23:30:00
BACH FIN

air 6.bat

air 6.bat

air-6.bat

air 6.bat

air-6.bat

cal-6.bat

bakēout.bat

bakeout.bat

bakeout.bat

bakeout.bat

bakeout.bat

bakeout.bat

cal_6.bat

air_6.bat

air 6.bat

air_6.bat

air 6.bat

air_6.bat

air 6.bat

air 6.bat

air 6.bat

air_6.bat

cal 6.bat

air-6.bat

air_6.bat

air_6.bat

air_6.bat

air-6.bat

air_6.bat

air 6.bat

air_6.bat

air 6.bat

air_6.bat

cal 6.bat

ais_6.bat

air-6.bat

air_6.bat

air 6.bat

air_6.bat

air 6.bat

air_6.bat

air_6.bat

air 6.bat

cal-6.bat

air 6.bat

air 6.bat

air 6.bat

air-6.bat
CLKFILE 7 . TXT

TIME

$00: 00: 00$

$00: 30: 00$

01:00:00

$01: 30: 00$

$02: 00: 00$

$02: 30: 00$

03:00:00

$03: 30: 00$

$04: 00: 00$

$04: 30: 00$

$05: 00: 00$

$05: 30: 00$

$06: 00: 00$

$06: 30: 00$

$07: 00: 00$

$07: 30: 00$

$08: 00: 00$

$08: 30: 00$

09:00:00

$09: 30: 00$

10:00:00

$10: 30: 00$

$11: 00: 00$

$11: 30: 00$

$12: 00: 00$

$12: 30: 00$

13:00:00

$13: 30: 00$

$14: 00: 00$

$14: 30: 00$

$15: 00: 00$

$15: 30: 00$

$16: 00: 00$

$16: 30: 00$

$17: 00: 00$

$17: 30: 00$

$18: 00: 00$

$18: 30: 00$

$19: 00: 00$

$19: 30: 00$

20:00:00

$20: 30: 00$

$21: 00: 00$

$21: 30: 00$

$22: 00: 00$

$22: 30: 00$

$23: 00: 00$

$23: 30: 00$
BATCH FILE

air_6.bat

air 6.bat

air 6.bat

air_6.bat

air_6.bat

air_6.bat

cal 6.bat

bakēout . bat

bakeout . bat

bakeout . bat

bakeout . bat

bakeout . bat

bakeout . bat

cal_6.bat

air 6.bat

air 6.bat

air-6.bat

air_6.bat

air_6.bat

air 6.bat

air_6.bat

air 6.bat

air_6.bat

cal 6.bat

air_6.bat

air 6.bat

air 6.bat

air 6. bat

air-6.bat

air 6.bat

air 6.bat

ai r-6.bat

air 6.bat

air 6.bat

cal 6.bat

air_6.bat

air 6.bat

air 6.bat

air 6.bat

air 6.bat

air 6.bat

air_6.bat

air 6.bat

air 6.bat

cal-6.bat

air_6.bat

air 6.bat

air_6.bat 


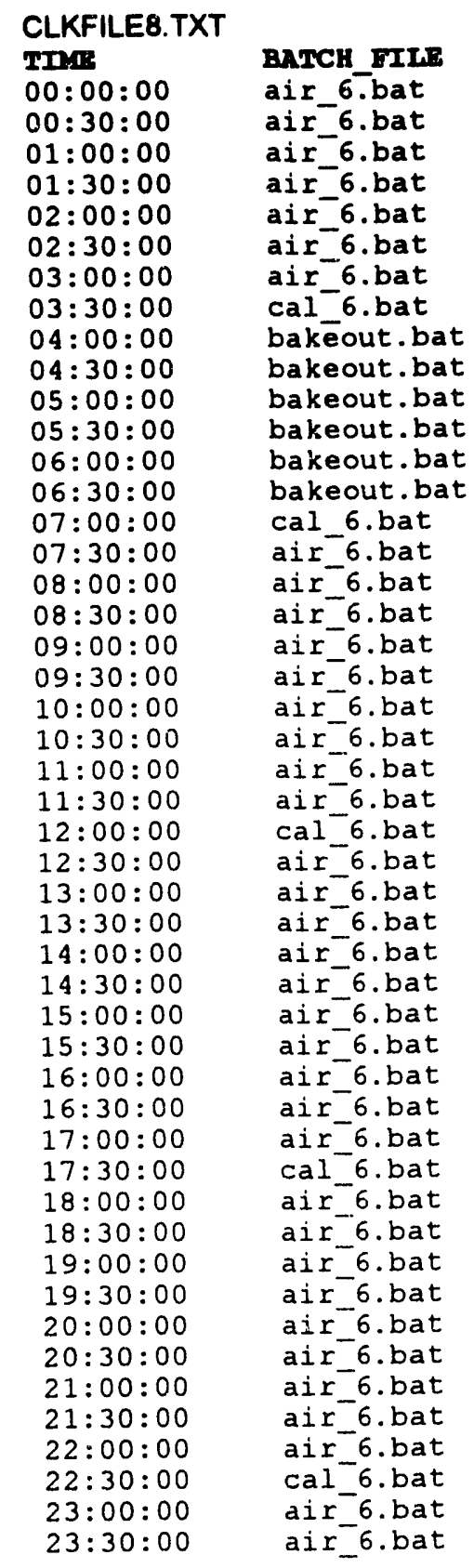


RANDRUN.C Flow Chart

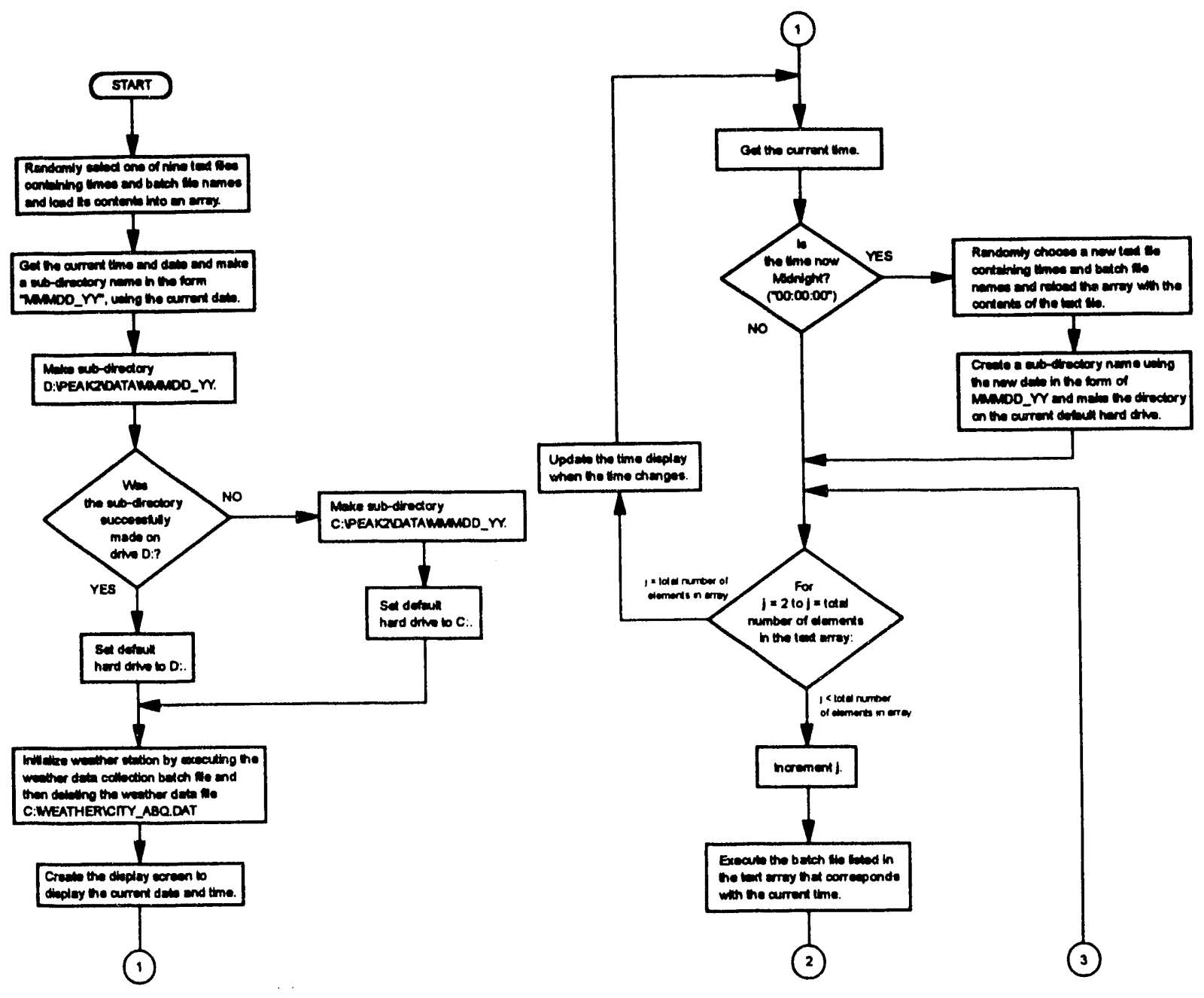




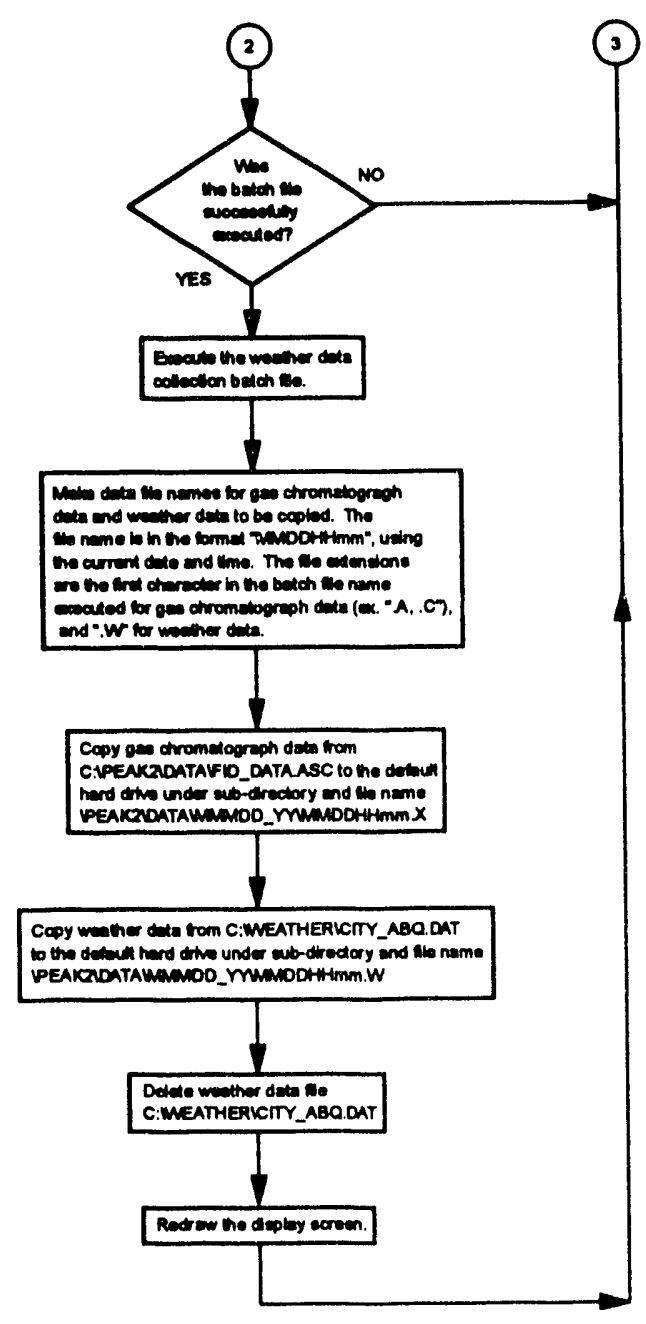

Randrun program listing

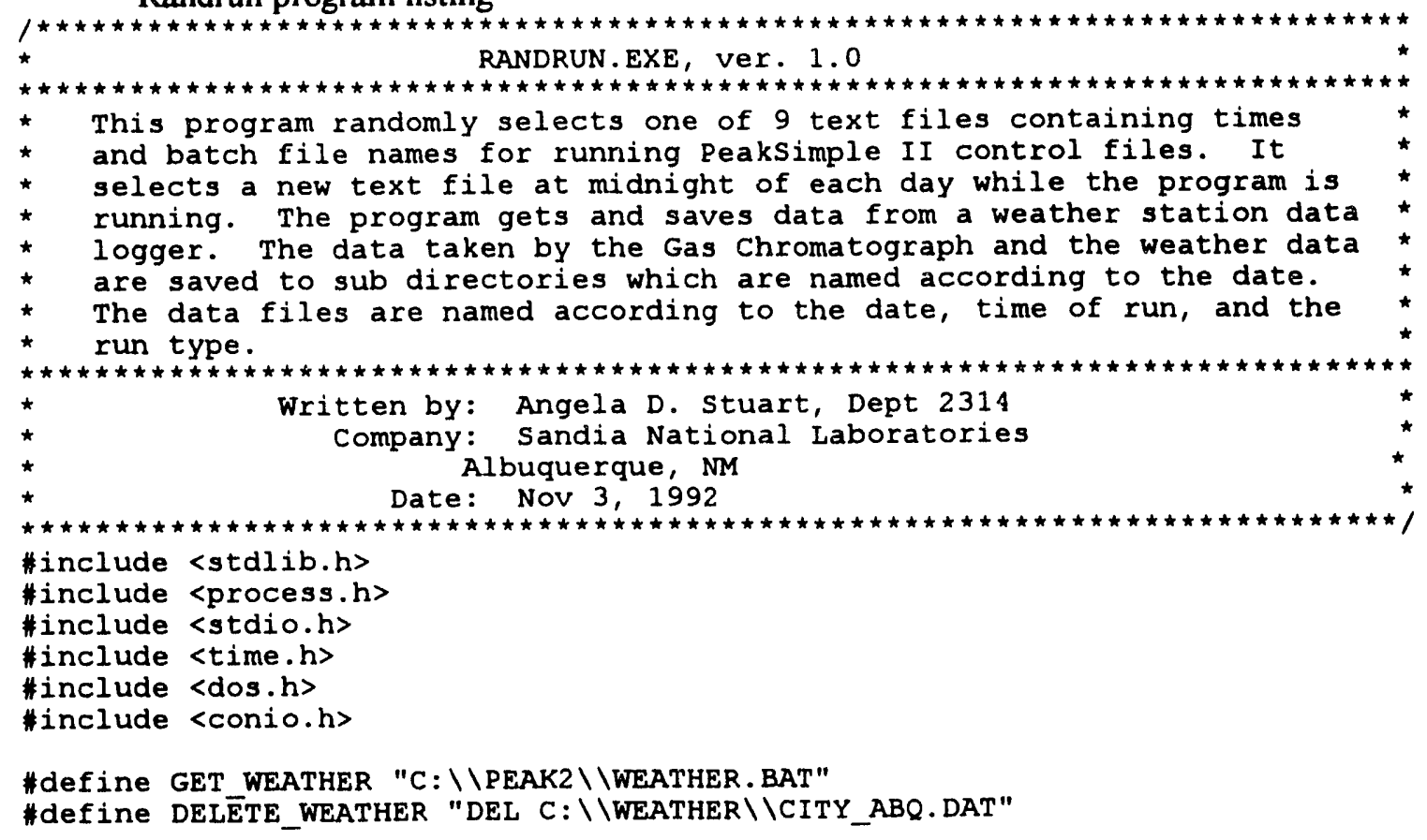




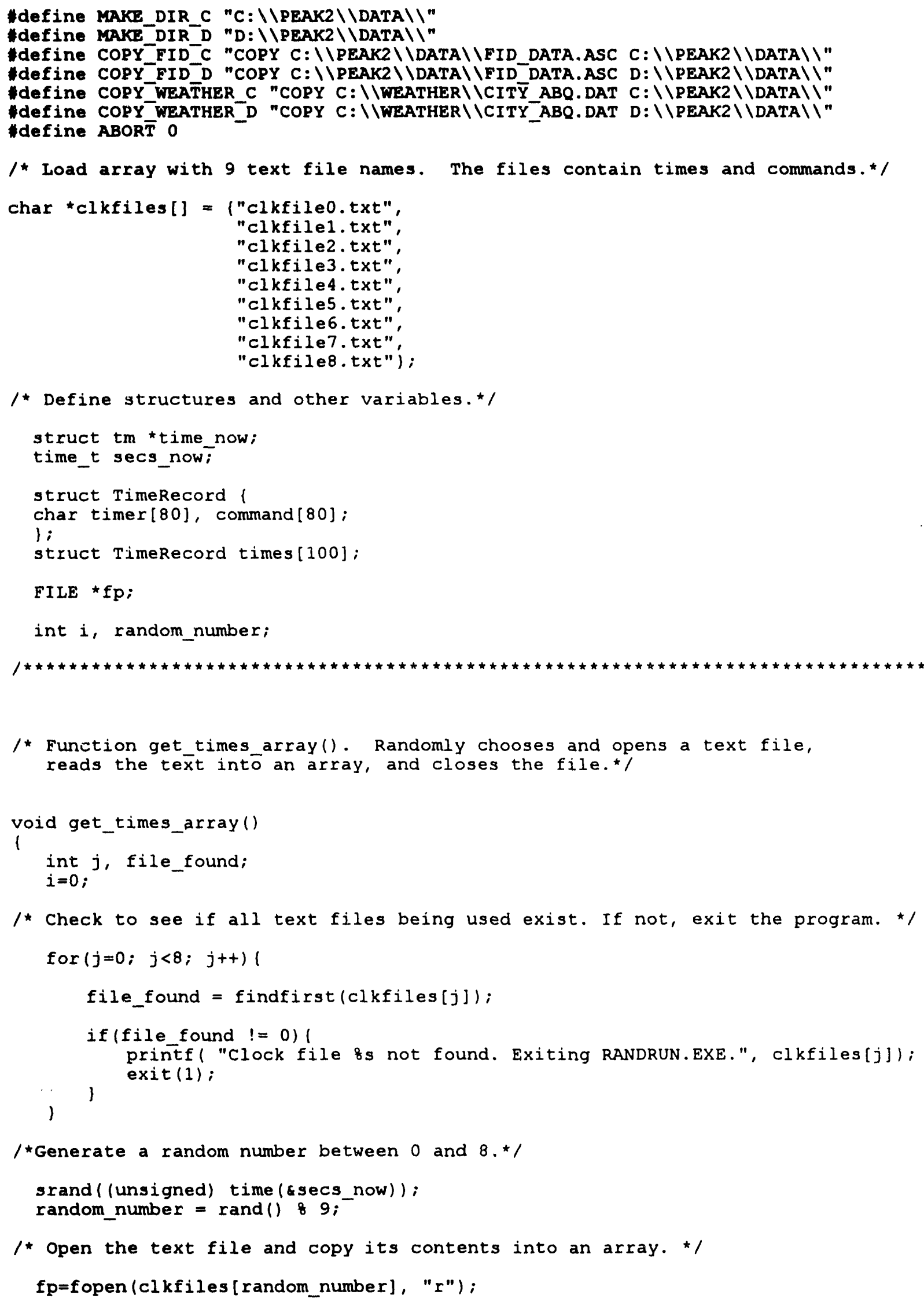




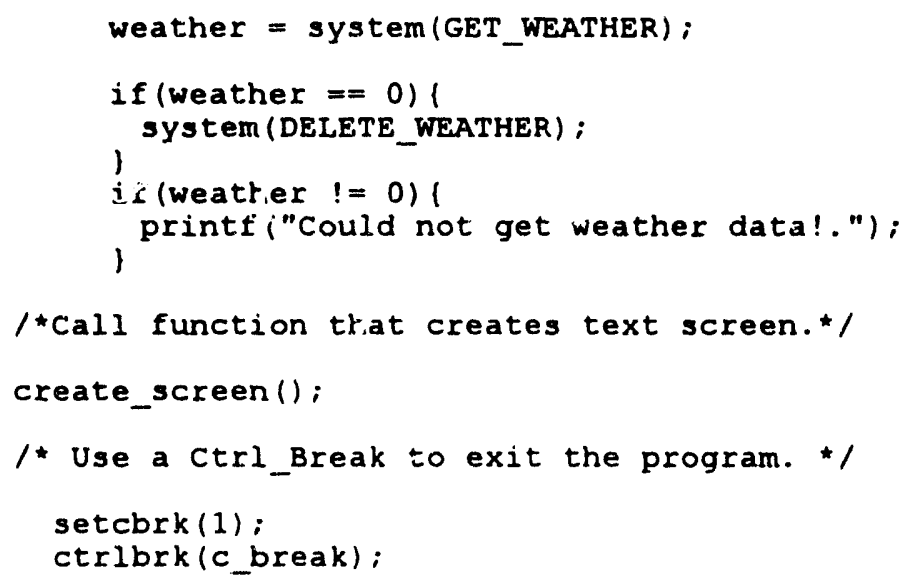

/* For each element of the array, compare the time listed in the array to the current time. If a match is found, run the indicated batch file, save the FID and weather data.*/

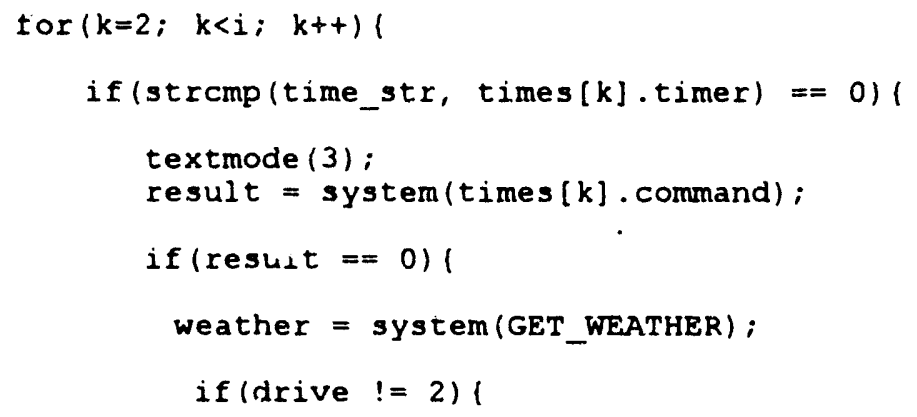




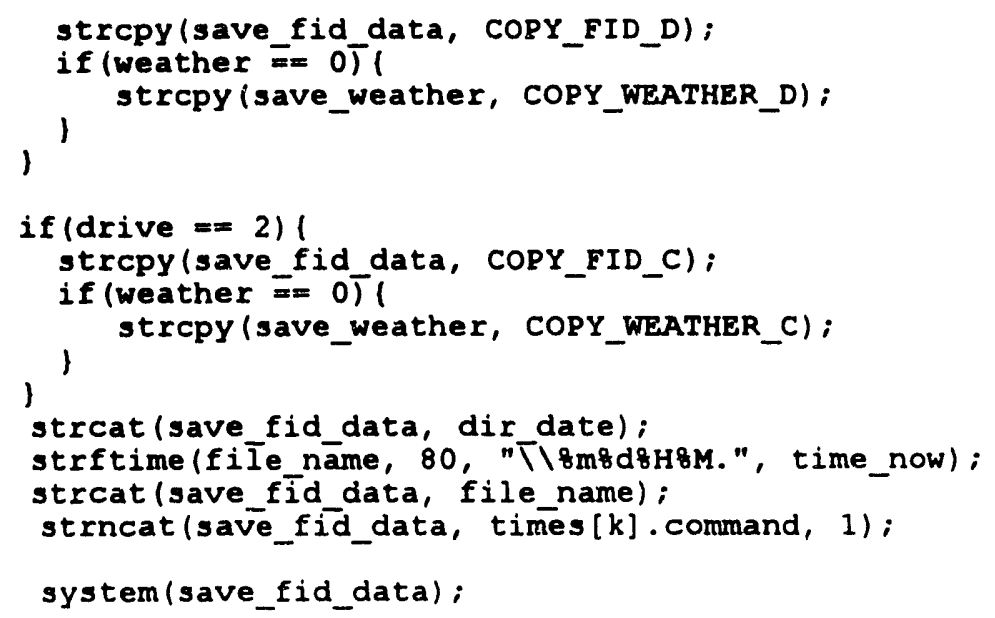


DISTRIBUTION:

3 City of Albuquerque

Air Pollution Control Division

$16600 \quad$ J. B. Woodard

Environmental Health Department

16602

16603

Attn: S. Walker

PO Box 1293

Albuquerque, NM 87103

16611

16611

56612

16612

11823 M. K. Alam

$1 \quad 1823$ S. M. Thornberg

16612 M.W. Moulton

12300 R. D. Andreas

12304 W. D. Williams

12314 M. J. Mundt

12314 A. D. Stuart

202337 G. R. Laguna

12337 F. J. Peter

16000 D. L. Hartley

16621 J. M. Phelan

17700 J. E. Stiegler

17725 H. A. Hwang

1 8523-2 Central Technical Files

57141 Technical Library

17151 Technical Publications

10 7613-2 Document Processing for DOE/OSTI 

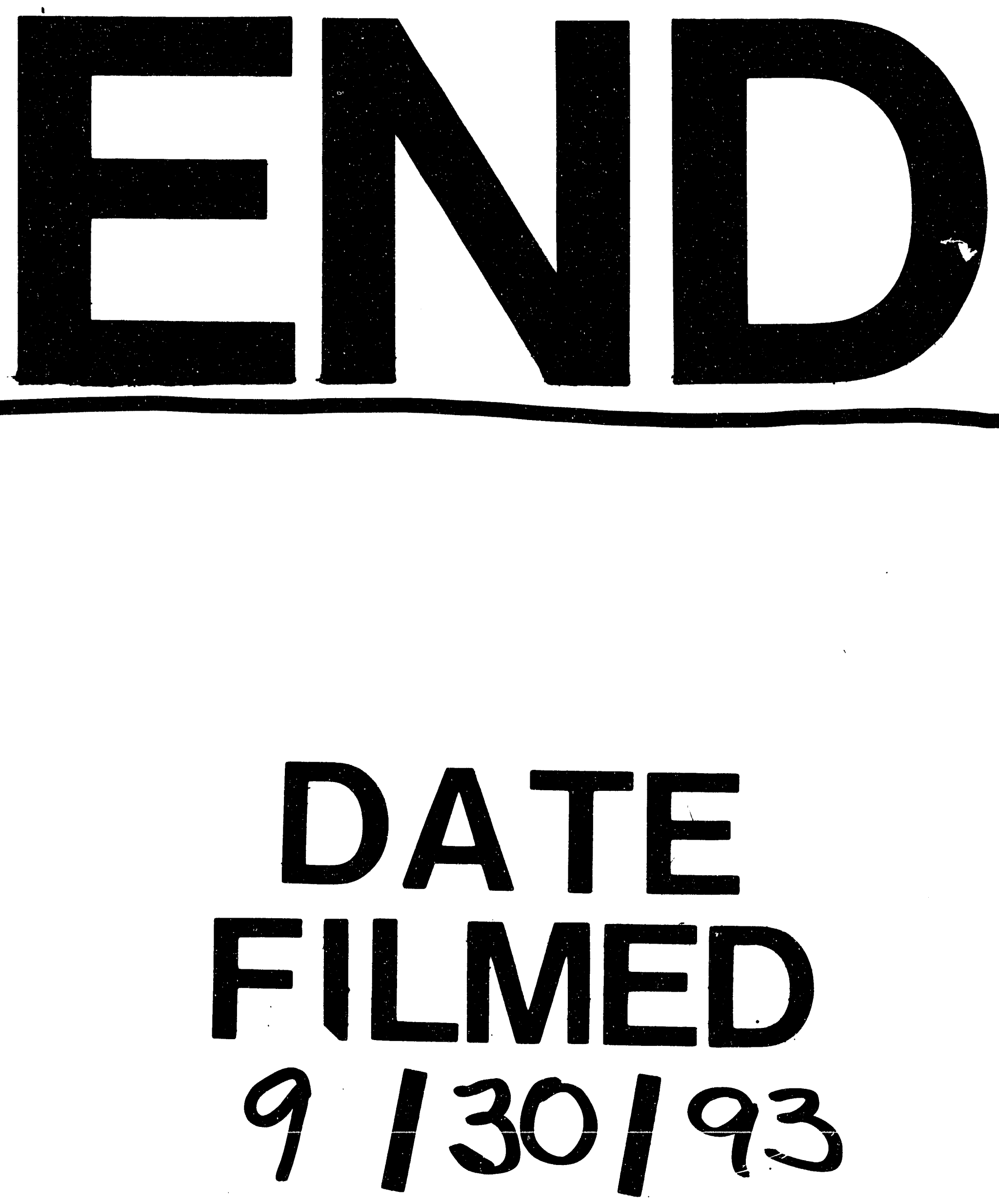


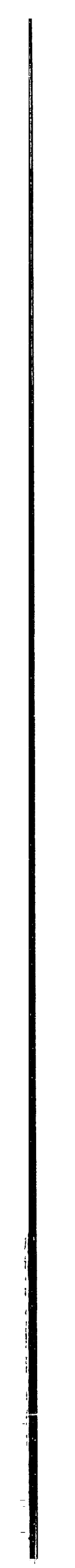

